\title{
Global gridded crop model evaluation: benchmarking, skills, deficiencies and implications
}

Christoph Müller $^{1}$, Joshua Elliott ${ }^{2,3}$, James Chryssanthacopoulos $^{2,3}$, Almut Arneth ${ }^{4}$, Juraj Balkovic ${ }^{5,6}$, Philippe Ciais $^{7}$, Delphine Deryng ${ }^{2,3}$, Christian Folberth ${ }^{5,8}$, Michael Glotter ${ }^{9}$, Steven Hoek ${ }^{10}$, Toshichika Iizumi ${ }^{11}$, Roberto C. Izaurralde ${ }^{12,13}$, Curtis Jones ${ }^{12}$, Nikolay Khabarov ${ }^{5}$, Peter Lawrence ${ }^{14}$, Wenfeng Liu ${ }^{15}$, Stefan Olin ${ }^{16}$, Thomas A. M. Pugh ${ }^{4,17}$, Deepak K. Ray ${ }^{18}$, Ashwan Reddy ${ }^{12}$, Cynthia Rosenzweig ${ }^{19,3}$, Alex C. Ruane ${ }^{19,3}$, Gen Sakurai $^{11}$, Erwin Schmid ${ }^{20}$, Rastislav Skalsky ${ }^{5}$, Carol X. Song ${ }^{21}$, Xuhui Wang ${ }^{7,22}$, Allard de Wit ${ }^{10}$, and Hong Yang ${ }^{15,23}$

${ }^{1}$ Potsdam Institute for Climate Impact Research, 14473 Potsdam, Germany

${ }^{2}$ University of Chicago and ANL Computation Institute, Chicago, IL 60637, USA

${ }^{3}$ Columbia University Center for Climate Systems Research, New York, NY 10025, USA

${ }^{4}$ Karlsruhe Institute of Technology, IMK-IFU, 82467 Garmisch-Partenkirchen, Germany

${ }^{5}$ International Institute for Applied Systems Analysis, Ecosystem Services and Management Program, 2361 Laxenburg, Austria

${ }^{6}$ Department of Soil Science, Comenius University in Bratislava, 84215 Bratislava, Slovak Republic

${ }^{7}$ Laboratoire des Sciences du Climat et de l'Environnement. CEA CNRS UVSQ Orme des Merisiers, 91191 Gif-sur-Yvette, France

${ }^{8}$ Department of Geography, Ludwig Maximilian University, 80333 Munich, Germany

${ }^{9}$ Department of the Geophysical Sciences, University of Chicago, Chicago, IL 60637, USA

${ }^{10}$ Earth Observation and Environmental Informatics, Alterra Wageningen University and Research Centre,

6708PB Wageningen, the Netherlands

${ }^{11}$ Institute for Agro-Environmental Sciences, National Agriculture and Food Research Organization, Tsukuba, 305-8604, Japan

${ }^{12}$ Department of Geographical Sciences, University of Maryland, College Park, MD 20742, USA

${ }^{13}$ Texas AgriLife Research and Extension, Texas A\&M University, Temple, TX 76502, USA

${ }^{14}$ Earth System Laboratory, National Center for Atmospheric Research, Boulder, CO 80307, USA

${ }^{15}$ Eawag, Swiss Federal Institute of Aquatic Science and Technology, 8600 Duebendorf, Switzerland

${ }^{16}$ Department of Physical Geography and Ecosystem Science, Lund University, 22362 Lund, Sweden

${ }^{17}$ School of Geography, Earth \& Environmental Sciences and Birmingham Institute of Forest Research,

University of Birmingham, Edgbaston, Birmingham, B15 2TT, UK

${ }^{18}$ Institute on the Environment, University of Minnesota, Saint Paul, MN, USA

${ }^{19}$ National Aeronautics and Space Administration Goddard Institute for Space Studies, New York, NY 10025, USA

${ }^{20}$ Institute for Sustainable Economic Development, University of Natural Resources and Life Sciences, 1180 Vienna, Austria

${ }^{21}$ Rosen Center for Advanced Computing, Purdue University, West Lafayette, IN, USA

${ }^{22}$ Sino-French Institute of Earth System Sciences, Peking University, 100871 Beijing, China

${ }^{23}$ Department of Environmental Sciences, University of Basel, Petersplatz 1, 4003 Basel, Switzerland

Correspondence to: Christoph Müller (christoph.mueller@pik-potsdam.de)

Received: 1 August 2016 - Discussion started: 20 September 2016

Revised: 5 January 2017 - Accepted: 2 March 2017 - Published: 4 April 2017 
Abstract. Crop models are increasingly used to simulate crop yields at the global scale, but so far there is no general framework on how to assess model performance. Here we evaluate the simulation results of 14 global gridded crop modeling groups that have contributed historic crop yield simulations for maize, wheat, rice and soybean to the Global Gridded Crop Model Intercomparison (GGCMI) of the Agricultural Model Intercomparison and Improvement Project (AgMIP). Simulation results are compared to reference data at global, national and grid cell scales and we evaluate model performance with respect to time series correlation, spatial correlation and mean bias. We find that global gridded crop models (GGCMs) show mixed skill in reproducing time series correlations or spatial patterns at the different spatial scales. Generally, maize, wheat and soybean simulations of many GGCMs are capable of reproducing larger parts of observed temporal variability (time series correlation coefficients $(r)$ of up to 0.888 for maize, 0.673 for wheat and 0.643 for soybean at the global scale) but rice yield variability cannot be well reproduced by most models. Yield variability can be well reproduced for most major producing countries by many GGCMs and for all countries by at least some. A comparison with gridded yield data and a statistical analysis of the effects of weather variability on yield variability shows that the ensemble of GGCMs can explain more of the yield variability than an ensemble of regression models for maize and soybean, but not for wheat and rice. We identify future research needs in global gridded crop modeling and for all individual crop modeling groups. In the absence of a purely observation-based benchmark for model evaluation, we propose that the best performing crop model per crop and region establishes the benchmark for all others, and modelers are encouraged to investigate how crop model performance can be increased. We make our evaluation system accessible to all crop modelers so that other modeling groups can also test their model performance against the reference data and the GGCMI benchmark.

\section{Introduction}

Agriculture is fundamental to human life and our ability to understand how agricultural production responds to changes in environmental conditions and land management has long been a central question in science (Russell, 1966; Spiertz, 2014). Numerical crop models have been developed over the last half-century to understand agricultural production systems and to predict effects of changes in management (e.g., irrigation, fertilizer; El-Sharkawy, 2011). In the face of continued population growth, economic development and the emergence of global-scale phenomena that affect agricultural productivity (most prominently climate change) crop models are also applied at the global scale (Rosenzweig and Parry, 1994). Given the importance of climate change and the cen- tral interest in agriculture, global-scale crop model applications have been increasingly used to address a wide range of questions, also beyond pure crop yield simulations (e.g., Bondeau et al., 2007; Del Grosso et al., 2009; Deryng et al., 2014; Osborne et al., 2013; Pongratz et al., 2012; Rosenzweig et al., 2014; Stehfest et al., 2007; Wheeler and von Braun, 2013).

With very few exceptions, crop models applied at the global scale have been developed for field-scale applications (e.g., EPIC-based models, pDSSAT, pAPSIM) or have been derived from global ecosystem models by incorporating field-scale crop model mechanisms and parameters (e.g., LPJ-GUESS, LPJmL, ORCHIDEE-crop, PEGASUS) and several of these have been systematically intercompared with a large number of other field-scale models (Asseng et al., 2013; Bassu et al., 2014). Still, differences between global gridded crop models (GGCMs) (Rosenzweig et al., 2014) and also between field-scale models (Asseng et al., 2013; Bassu et al., 2014; Li et al., 2015) have been recently identified, following a general call to revisit modeling skills and approaches (Rötter et al., 2011), which is also a central objective of the Agricultural Model Intercomparison and Improvement Project (AgMIP) (Rosenzweig et al., 2013) and the Inter-Sectoral Impact Model Intercomparison Project (ISIMIP) (Warszawski et al., 2014). Site-specific applications and model evaluation can demonstrate the general suitability of the mechanisms implemented in the models and the corresponding parameters (Boote et al., 2013), but the extrapolation and upscaling of parameters and model assumptions remains challenging (Ewert et al., 2011; Hansen and Jones, 2000). If models are applied at the global scale, they also need to be assessed at the scale of interpretation, which ranges from gridded to national or regional aggregates (Elliott et al., 2014a; Fader et al., 2010; Müller and Robertson, 2014; Nelson et al., 2014a, b; Osborne et al., 2013).

Global-scale applications of crop models face a number of challenges. A major difference to field-scale model applications is that at large regional- to global-scale detailed model calibration to field observations is not possible. Specification and initialization as typically conducted in field-scale applications simply lack data of suitable spatial coverage, and simulation units (e.g., $0.5^{\circ}$ grid cells) represent an aggregate of many smaller, potentially heterogeneous fields. Initialization of soil properties (Basso et al., 2011) is especially important in dry and nutrient-depleted production systems (Folberth et al., 2012) and the specification of soil properties can greatly affect crop model simulations (Folberth et al., 2016b). Similarly, production systems typically cannot be specified in great detail. There is limited information on growing seasons (Portmann et al., 2010; Sacks et al., 2010) and irrigation area, amount and timing (Siebert et al., 2015; Thenkabail et al., 2009) that can be used to model crop-specific irrigation shares (Portmann et al., 2010; You et al., 2010), planting dates and crop parameters for the specification of varieties grown (van Bussel et al., 2015) and multiple crop- 
ping rotation practices. Still, crop varieties are often assumed to be homogeneous globally or within large regions in global model setups (Folberth et al., 2016a; Müller and Robertson, 2014). Other management aspects are typically assumed to be static in space and time. There have been some attempts to calibrate crop models in global-scale applications but these always calibrate to (sub-)national yield statistics (Fader et al., 2010) or to gridded yield data sets (Deryng et al., 2011; Sakurai et al., 2014) that are based on (sub-)national statistics (Iizumi et al., 2014b; Mueller et al., 2012).

The evaluation of model performance (skill) faces similar challenges. Data availability has improved lately, as gridded data sets on yield time series have become available (Iizumi et al., 2014b; Ray et al., 2012), but generally only yield data are available, while other end-of-season (e.g., biomass) or within-season (e.g., leaf area index, LAI) information is lacking. The gridded yield data sets are not purely observational but include some form of model application in the interpolation of unknown accuracy so that they do not directly qualify as a reference data set. Currently, global gridded crop models lack a clear benchmark against which they can be evaluated. A benchmark is an a priori definition of expected model performance based on a set of performance metrics (Best et al., 2015). Given that the GGCMs are merely driven by variable information on weather and atmospheric $\mathrm{CO}_{2}$ concentrations, whereas assumptions on soil properties and/or management systems are static, these cannot be expected to reproduce all temporal dynamics and spatial patterns of observed crop yields. The contribution of weather variability has been estimated to roughly one-third globally of the observed yield variability (Ray et al., 2015) and moderate-tomarked yield losses can be explained by weather data over 26-33\% of the harvested area (Iizumi et al., 2013), with a clear negative impact of extreme drought and heat events (Lesk et al., 2016). The explanatory power of weather variability on crop yields varies strongly between regions, with a tendency to have a larger influence on yield variability in high-input systems than in low-input systems (Ray et al., 2015), where substantial variation may also be introduced by pests and diseases, socio-economic conditions and changes in management.

The comparison with gridded data is difficult, because of introduced interpolation errors in the referenced data. The differences between the two gridded yield reference data sets can be substantial, indicating that the modeling assumptions made introduce substantial uncertainty and limit their applicability as a reference data set. Similarly, if simulated gridded yield data are to be compared with (sub-)national yield statistics, these need to be spatially aggregated. This aggregation requires information on the spatial and temporal distribution of cropland and irrigation systems, which is available from different global data sets with differing estimates that can introduce substantial uncertainty (Porwollik et al., 2017).
The objective of this paper is to provide and discuss a broad model evaluation framework to test performance of GGCMs that participated in the global gridded crop model intercomparison (GGCMI) of AgMIP's Gridded Crop Model Initiative (Ag-GRID; Elliott et al., 2015). We aim to assess general and individual model performance across different crops and regions that can serve as a basis for further model development and improvement as well as a benchmark for future assessments. Model performance is evaluated with respect to correct spatial patterns as well as temporal dynamics at the global scale as well as for individual countries and grid cells. Reference data sets and metrics are explained in more detail in the methods section. We also propose this evaluation system to become a standard benchmarking system for all global gridded crop model application and to track model improvement. ${ }^{1}$ Therefore, we make the data processing and the computation of performance metrics available online (https://mygeohub.org/tools/ggcmevaluation) to other modelers so that they can compare their models' results against the GGCMI ensemble. We argue that under given uncertainties, the best performing crop model per region and crop defines the benchmark for the other models.

\section{Methods}

\subsection{Models participating and experimental setup}

For the GGCMI in AgMIP, 14 model groups have contributed (Table 1), following the protocol for the GGCMI (Elliott et al., 2015). For this, crop modeling groups were asked to perform global simulations with their standard assumptions (inputs or internal calculations) on growing seasons and fertilizer inputs ("default"), with harmonized growing seasons (i.e., with supplied planting and harvest dates; Elliott et al., 2015) and fertilizer inputs per crop and pixel ("fullharm") as well as a simulation with harmonized growing seasons but assuming the absence of nutrient limitation ("harm-suffN"; referred to as "harmnon" in Elliott et al. (2015), but changed here to avoid the misinterpretation of "no nitrogen"). We evaluate model performance for each of these harmonization sets to study the importance of these assumptions for individual models' as well as for the ensemble's performance. More detail on the processes implemented in the GGCMs can be found in the Supplement, Tables S1-S4.

Here we use data from simulations by these 14 GGCMs driven by the weather data set AgMERRA (Ruane et al., 2015), for which all modeling groups have performed simulations and historical atmospheric carbon dioxide $\left(\mathrm{CO}_{2}\right)$ concentrations (Thoning et al., 1989). The AgMERRA data set spans the time frame of 1980-2010 and provides daily data

\footnotetext{
${ }^{1}$ We supply an online evaluation system where files can be uploaded and assessed in the same way as the GGCMI simulations in this paper. The tool is available on the GEOSHARE Portal at https://mygeohub.org/tools/ggcmevaluation.
} 
Table 1. GGCMs participating in the study, model type and key references.

\begin{tabular}{lll}
\hline Crop model & Model type & Key literature \\
\hline CGMS-WOFOST & Site-based process model & de Wit and van Diepen (2008) \\
CLM-Crop & Ecosystem Model & Drewniak et al. (2013) \\
EPIC-BOKU & Site-based process model (based on EPIC) & EPIC v0810 - Izaurralde et al. (2006), Williams (1995) \\
EPIC-IIASA & Site-based process model (based on EPIC) & EPIC v0810 - Izaurralde et al. (2006), Williams (1995) \\
EPIC-TAMU & Site-based process model (based on EPIC) & EPIC v1102 - Izaurralde et al. (2012) \\
GEPIC & Site-based process model (based on EPIC) & EPIC v0810 - Liu et al. (2007), Williams (1995), Folberth et al. (2012) \\
LPJ-GUESS & Ecosystem Model & Lindeskog et al. (2013), Smith et al. (2001) \\
LPJmL & Ecosystem Model & Waha et al. (2012), Bondeau et al. (2007) \\
ORCHIDEE-crop & Ecosystem Model & Wu et al. (2016) \\
pAPSIM & Site-based process model & APSIM v7.5 - Elliott et al. (2014b), Keating et al. (2003) \\
pDSSAT & Site-based process model & pDSSAT v1.0 - Elliott et al. (2014b), DSSAT v4.5 - Jones et al. (2003) \\
PEGASUS & Ecosystem model & v1.1 - Deryng et al. (2014), v1.0 - Deryng et al. (2011) \\
PEPIC & Site-based process model (based on EPIC) & EPIC v0810 - Liu et al. (2016), Williams (1995) \\
PRYSBI2 & Empirical/process hybrid & Sakurai et al. (2014) \\
\hline
\end{tabular}

on the most important meteorological driver variables and groups applied their own interpolation to sub-daily values if needed. If additional weather data were needed by individual modeling groups (such as long-wave radiation), these were supplemented from the Princeton Global Forcing data set (PGFv2) (Sheffield et al., 2006). We assume this to have little impact on simulation results, as all data sets are based on station data and/or re-analysis data, and as bias correction of re-analysis data is performed for each meteorological variable individually, there is no explicit dependency between individual variables (e.g., between radiation and temperature). The contribution of uncertainties in historic weather data sets on crop model skill is to be evaluated elsewhere and is not part of the objectives here.

All input and harmonization targets are supplied at a regular grid with $0.5^{\circ}$ resolution. Weather data are supplied at daily resolution. Some models use a different spatial or temporal resolution for which they had to find individual solutions. See text and Table S2 in the Supplement for further detail. Each modeling group is asked to use their own soil data and parameterization (Elliott et al., 2015). Yield simulations are conducted for the four major crops wheat, maize, rice and soybean depending on model capacities. Some groups could not supply data for all crops or harmonization settings (see Table 2). Each modeling group supplied data for each crop for all land grid cells (up to 62911 grid cells) with separate simulations for purely rain-fed conditions and for conditions with full irrigation. Full irrigation does not necessarily imply the absence of water stress in all models, if, e.g., the atmospheric water vapor pressure deficit exceeds the plant's physical capacity to transpire water. Model irrigation is triggered on demand (Supplement Table S2) independent of the availability of irrigation water (Elliott et al., 2015).

Following FAO reporting standards, we are not reporting simulated yield data as calendar aggregates but as a time series of annual growing seasons. In this way, we avoid that individual calendar years can have two harvests (one shortly after 1 January and one shortly before 31 December) and others with zero harvest, which would greatly increase the variability in the reported simulated crop yields and would be inconsistent with FAO data. Instead, each harvest season is assigned a calendar year, starting with the first harvest of the growing season that started in 1980 (beginning of the AgMERRA forcing data), leaving a residual uncertainty how the time series need to be matched (see below).

\subsection{Reference data}

We use two different data sets for the evaluation of the GGCMs. The FAO data (FAOstat data, 2014) are used for national and global-scale model evaluation and are available at these scales from 1961 to 2013. For some countries, production data and/or harvested areas have been estimated by the FAO rather than reported (FAOstat data, 2014). For spatially resolved detail we use the data published by Ray et al. (2012, henceforth "Ray2012"), as that allows for direct comparison with the regression model analysis of Ray et al. (2015, henceforth "Ray2015"). The Ray2012 data span 1961-2008 and were aggregated from its original resolution of 5 arcmin to the $0.5^{\circ}$ GGCMI standard resolution, weighted by production. Both production and harvested area data are collected at sub-national level for 51 countries in the Ray data and changes in productivity thus reflect both dynamics in area and production. National totals are forced to match FAO statistics, if there were differences (Ray et al., 2012). The assignment of yield statistics to the grid raster as conducted by Ray et al. (2012) requires making assumptions that introduce uncertainty. To illustrate the uncertainty in the gridded reference data, we compare the Ray 2012 data with the Iizumi data set (Iizumi et al., 2014b). The Iizumi data set is available in gridded form from 1982 to 2006, which we here re-gridded from its original resolution of $1.125^{\circ} \times 1.125^{\circ}$ to the standard GGCMI resolution of $0.5^{\circ} \times 0.5^{\circ}$ resolution, using the remapcon function (CDO, 2015). As much of the Southern 


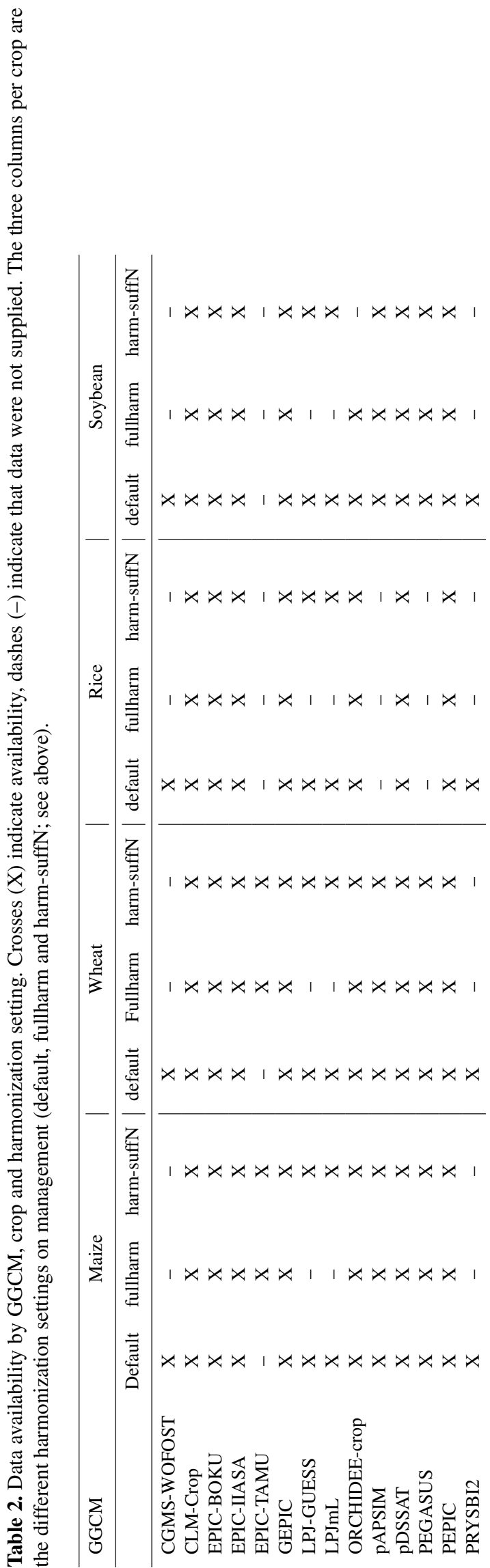

Hemisphere has no data for 2006 due to its ending in the middle of Southern Hemisphere summer, we only consider the period 1982-2005 here. The Iizumi data are based on national FAO data and the spatial variability within countries is introduced based on satellite data. Given the different approaches, there are substantial differences in spatial patterns between the Ray and Iizumi data, but temporal dynamics at the national level reflect the FAO data.

\subsection{Metrics used}

In the analysis we largely focus on time series correlation of simulated and reference crop yields, given that the main application of gridded crop models at the global scale is related to studies on climate change impacts, where we expect models to respond reasonably to changes in atmospheric conditions (weather, climate). The main metric used is therefore the time series correlation analysis, employing the Pearson's product moment correlation coefficient (henceforth "correlation coefficient"). Significance levels ( $p$ values) are reported based on a $t$ distribution with length $(x)-2^{\circ}$ of freedom. Given difficulties in attributing sequences of growing periods to the calendar year in both FAO statistics ${ }^{2}$ and in simulated data where groups also interpreted the reported standards differently, we test if the time series correlation can be substantially improved by shifting the times series by 1 year. We apply such shifts only if the correlation coefficient improves by at least 0.3 and report un-shifted time series analyses in the supplement. Time series correlation is used at the global aggregation level, the national aggregation and the pixel level. In some cases, the correlation analysis is weighted by production to put higher emphasis on larger production units, assuming that data quality is often better than for smaller producer units (e.g., less developed countries) and because these are more important to correctly simulate for global assessments. At the global scale, correlation coefficients are simply reported in the figures but we employ heatmaps to display correlation coefficients at the national scale, making use of a version of the heatmap.2 function of the gplot package (Warnes et al., 2016), which has been modified to allow for extra labeling.

We acknowledge that the models are only driven by fields of weather data, soil data and nitrogen fertilizer inputs, ignoring the heterogeneity in patterns of other fertilizers (e.g., $\mathrm{P}, \mathrm{K}$ ), pest control and other managerial aspects (e.g., varieties, planting densities). Therefore, we only test model performance in reproducing spatial patterns of productivity at national aggregations and not within individual countries, as the quality of gridded reference data Ray2012 (interpolated

\footnotetext{
${ }^{2}$ FAO glossary on crop production: “... When the production data available refers to a production period falling into two successive calendar years and it is not possible to allocate the relative production to each of them, it is usual to refer production data to that year into which the bulk of the production falls." Available at http://faostat3.fao.org/mes/glossary/E
} 
(sub-)national statistics) as well as fertilizer inputs (Elliott et al., 2015; Mueller et al., 2012) and growing seasons (Elliott et al., 2015; Portmann et al., 2010; Sacks et al., 2010) is limited with respect to the spatial heterogeneity. Deviations from national or global yield levels are computed as the mean bias, as in Eq. (1), where $i$ is any element in $n$. At the global scale and for individual countries, $n$ is the number of growing seasons in the sample.

bias $=\frac{1}{n} \sum_{i=1}^{n}\left(\right.$ yield $_{\text {sim }, i}-$ yield $\left._{\text {obs }, i}\right)$

For a more comprehensive testing of the simulated yield dynamics, we employ Taylor diagrams that allow for displaying the correlation in spatiotemporal patterns between observations and simulated data in a single diagram (Taylor, 2001). The Taylor diagram depicts the correlation coefficient across spatial units and time, the centered root mean squared difference (RMSD), and the variance relative to that of the observational data set. Acknowledging the difficulties with respect to the spatial heterogeneity in reference and simulated data, we employ the Taylor diagrams only for nationally aggregated data, meaning that spatial patterns only refer to national aggregations here. In the Taylor diagram analysis, countries are weighted by their crop-specific production (FAOstat data, 2014). To disentangle the contribution of the spatial vs. the temporal variability to the Taylor diagram, we also compute two variants of these diagrams, which focus on temporal or spatial variability only. For the temporaldynamics-only variant, we remove the national means from all de-trended time series so that all national time series have a mean of zero and thus display no differences in this respect. For the space-dynamics-only variant, we average time series so that we compute the metrics with one national mean value per country only, ignoring possible changes in data quality over the time series. For plotting Taylor diagrams, we use the taylor.diagram function of the $\mathrm{R}$ package plotrix (Lemon, 2006), which we have modified to allow for weighted correlation and for testing of significance levels.

Instead of numerous maps on pixel-specific performance metrics, we also present these in the form of box plots. To allow for weighting the distribution of pixel-specific metrics such as the correlation coefficients, we employ weighted quantiles of the function quantileWt of the R package simPopulation (Alfons and Kraft, 2013).

\subsection{Data processing}

Gridded crop model simulations are driven by time series of weather data and of atmospheric $\mathrm{CO}_{2}$ concentrations, and static management assumptions. A comparison to observation-based reference data thus requires processing of raw simulation GGCM outputs and the reference data to make these different data sources comparable. As much of the trends in yield are driven by intensification and altered management (FAO, 2013; Ray et al., 2012), we are remov- ing trends from simulation and reference data. As reference data are available at grid cell, national and global levels, we aggregated simulated yield data to grid cell, national and global levels, using an area-weighted average as described in Eq. (2). Aggregation to the grid cell level only describes the combination of irrigated and rain-fed simulation time series, but follows the same principle.

$$
\begin{aligned}
& \text { yield }_{\text {aggregated }, t}= \\
& \frac{\sum_{i=1}^{n} \text { yield }_{i, \mathrm{ri}, t} \times \text { area_irrigated }_{i, t}+\sum_{i=1}^{n} \text { yield }_{i, \mathrm{rf}, t} \times \text { area_rainfed }_{i, t}}{\left.\sum_{i=1}^{n} \text { area_irrigated }_{i, t}+\text { area_rainfed }_{i, t}\right)}
\end{aligned}
$$

Here, $i$ is the index of any grid cell assigned to the spatial unit in question for growing season $t, n$ is the number of grid cells in that spatial unit, yield $i$,ir,t is the simulated yield $\left(\mathrm{tha}^{-1}\right)$ under fully irrigated conditions in grid cell $i$, and yield $\mathrm{d}_{i, \mathrm{rf}, t}$ is the simulated yield $\left(\mathrm{tha}^{-1}\right)$ under rain-fed conditions in grid cell $i$, area_irrigated ${ }_{i}$ is the irrigated harvested area (ha) in grid cell $i$ and area_rainfed ${ }_{i}$ is the rain-fed harvested area (ha) in grid cell $i$.

Following Porwollik et al. (2017), we use four different masks for the aggregation to national data: MIRCA2000 (Portmann et al., 2010), SPAM (You et al., 2014a, b), Iizumi (Iizumi et al., 2014b) and Ray (Ray et al., 2012). As we cannot assess which of these aggregation masks is superior to the others, we always select the aggregation mask that gives the best agreement between simulated and reference time series. MIRCA2000 and SPAM provide separate data on irrigated and rain-fed crop-specific harvested areas per grid cell, while Ray and Iizumi do not distinguish irrigated from rainfed areas. For aggregation purposes, we thus separate total harvested area per grid cell and crop from Ray and Iizumi into irrigated and rain-fed areas, using the relative shares per grid cell and crop from MIRCA2000 (see Porwollik et al., 2017).

After aggregation to national time series or to grid-cellspecific area-weighted combinations of irrigated and rain-fed yield simulations, we remove trends from simulated and reference data. For this, we are computing the anomalies by subtracting a moving mean average of a 5-year window $(t-2$ to $t+2)$, with 3 -year windows at both ends $(t-1$ to $t+1)$ of the time series in order to not lose too many years from the time series. Similar de-trending methods have been applied by other studies (Iizumi et al., 2014a, 2013; Kucharik and Ramankutty, 2005). We also tested other de-trending methods (e.g., linear or quadratic trend removal) and find that this may also results in better agreement between simulated and reference data sets. However, for simplicity we focus on one de-trending method only in this analysis. For evaluation across different countries, de-trended time series can be compared as pure anomalies, which vary around zero, or with preserved national mean yields allowing also for assignment of differences in yield levels between different countries. 
For a comparison of simulated yields that are reported in tha $^{-1}$ dry matter with FAOstat yields (FAOstat data, 2014), which are reported in $\mathrm{t} \mathrm{ha}^{-1}$ "as purchased", we assume a net water content of $12 \%$ for maize and wheat, $13 \%$ for rice and $9 \%$ for soybean, following Wirsenius (2000). This assumption does not affect any metrics other than the mean bias.

\subsection{Benchmarks for evaluating model performance}

GGCM simulations are typically used to study effects of changing environmental conditions, such as climate change impact assessments. We therefore put much emphasis on the models' ability to reproduce temporal variability. Also the spatial variability of crop yields; e.g., along environmental gradients within countries or in response to different fertilizer input within and between countries should be reproduced by the models.

We apply weights when assessing model performance. For analyses of aggregated yield data, it is important to get large areas and highly productive areas right in the simulations. Also, reference data are often of limited quality for marginal and/or small areas. We therefore typically weight results by production (harvested area multiplied with productivity).

At pixel scale, we are presenting skill-based model ensemble estimates by selecting the single best GGCM per pixel that demonstrate the joint ensemble skill rather than an average (e.g., median) across all models. This skill-based approach demonstrates to what extent crop models can actually reproduce observed patterns and variability and differences between individual models and the skill-based model ensemble quantify the learning potential within the ensemble. Principally, in the absence of other benchmark measures, the best performing model should be the benchmark for the others. For the definition of the benchmark here, we consider not only the GGCMI ensemble but also the 27 regression models as used by Ray et al. (2015). A model-based benchmark as postulated here can establish a very low target, e.g., if all models perform poorly. Therefore, the benchmark will have to be continuously re-assessed and model intercomparison studies as the GGCMI can help to further develop this benchmark.

\section{Results}

We present results from the evaluation for three different aggregation levels: global, national and grid cell level. The global level is the most aggregate where underlying reasons for observed patterns are hard to identify. National-level data provide more insights on underlying patterns but require data reduction for presentation. Pixel-level results can only be assessed by statistical means and results are thus presented in aggregated form again. We typically display results for the default setting in the main text but supply results for all other settings in the supplement. For the main text figures, we use fullharm simulations for all those model-crop combinations that did not supply a default setting simulation (i.e., those that did not have a default setting before participating in GGCMI). These are clearly indicated in figures and captions. Also, to reduce the amount of data displayed here, we typically show results for maize in the main text and display figures for all other crops in the supplement, while still describing and discussing these here.

\subsection{Global-scale model performance}

Aggregated to global time series of crop yields, the different GGCMs display mixed skill in comparison to the FAOstat time series when both are de-trended. Of the four major crops, global yield variability can be best reproduced for maize with correlation coefficients $(r)$ between 0.89 and 0.42 and one non-significant correlation (PRYSBI2, Fig. 1). PRYSBI2 is actually parameterized to reproduce the historic trend in crop yields and if trends are not removed prior to the time series correlation analysis, its correlation becomes highly significant with a correlation coefficient of 0.56 . Note that a correlation analysis that includes a trend to which the model has been calibrated may be strongly dominated by this trend. Changes in the harmonization setting (fullharm, harmsuffN; see Figs. S1 and S2 in the Supplement) often have little effect on simulations except for a few models, where harmonization can significantly improve (e.g., EPIC-BOKU) or weaken (e.g., PEGASUS) the correlation.

For wheat, 10 of the 14 models produce a time series that is significantly correlated to FAO statistics (Fig. 2) with correlation coefficients between 0.67 and 0.37. Harmonization does not greatly change correlation coefficients but two models achieve significant correlation under harmonization that they did not achieve in the default setting (GEPIC, ORCHIDEE-crop), whereas one loses the significant correlation under harmonization (PEGASUS; see Figs. S3-S4). PRYSBI2 again only achieves significant correlation if trends are not removed prior to the correlation analysis.

Only 3 of the 11 GGCMs that submitted data for rice (Table 2) achieve significant correlation to FAO statistics of variations in global rice productivity (EPIC-IIASA, LPJ-GUESS and PRYSBI2; Fig. 3) and two others achieve significant correlations under fullharm (EPIC-BOKU, PEPIC; Fig. S5), but none of the models reach statistical significance under the harm-suffN setting (Fig. S6). PRYSBI2's correlation improves substantially (from $0.53 *$ to $0.83 * * *$ ) if trends are maintained.

Of the 13 GGCMs that submitted data for soybean (Table 2), seven achieve significant correlation to FAO statistics of variations in global soybean productivity (correlation coefficients between 0.64 and 0.41 ). Under harmonization, two more models reach statistical significance levels (LPJGUESS, PEPIC; Figs. S7-S8), and PRYSBI2 reaches significant correlations $\left(0.57^{* *}\right)$ if trends are not removed. 


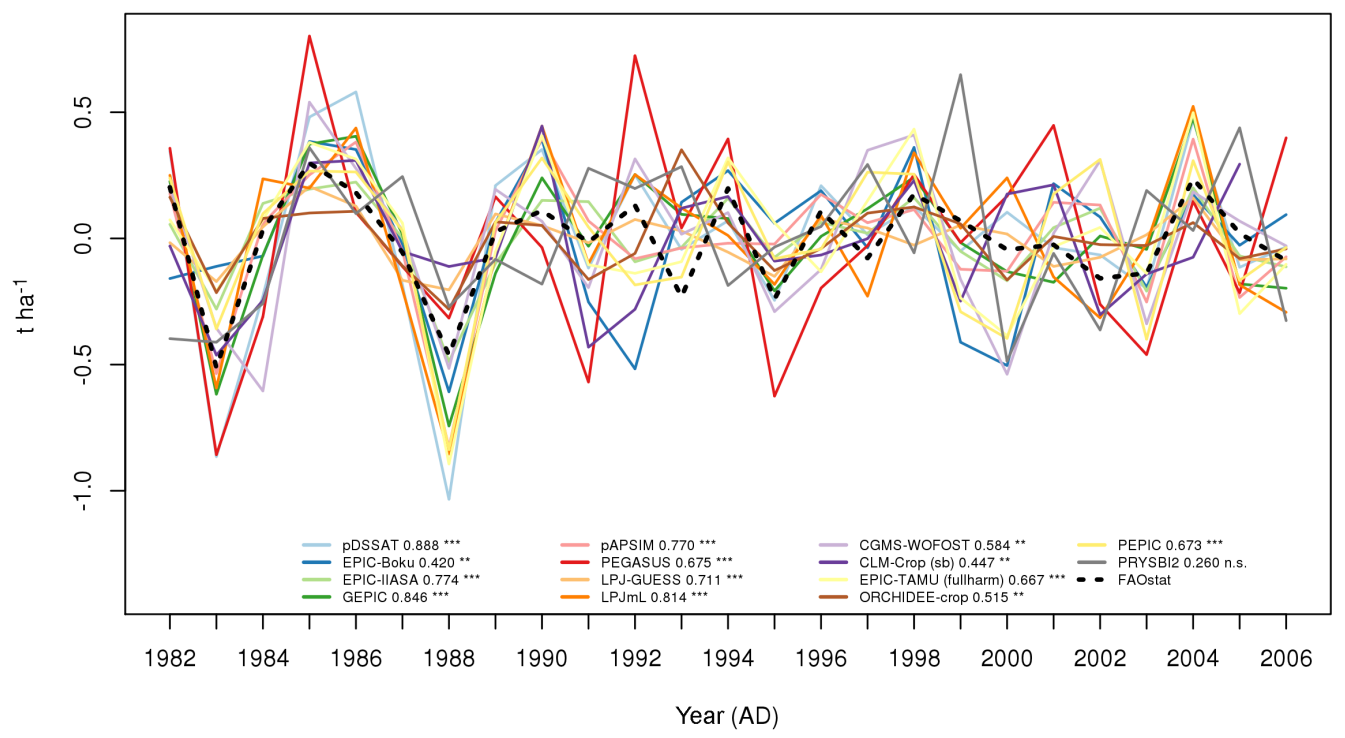

Figure 1. Time series of GGCMI simulations (solid colored lines) and FAOstat reference data (dashed line) for maize after de-trending. Numbers in the legend next to model names indicate the Pearson correlation coefficient, asterisks indicate the $p$ values (*** for $p<0.001$, ** for $p<0.05$, * for $p<0.1$, n.s. for not significant). This figure displays the "default" setting, except for EPIC-TAMU, which only supplied the fullharm setting simulations (see Table 2). The ( $\mathrm{sb}$ ) flag indicates that the time series had been shifted backwards by a year to achieve a better match.

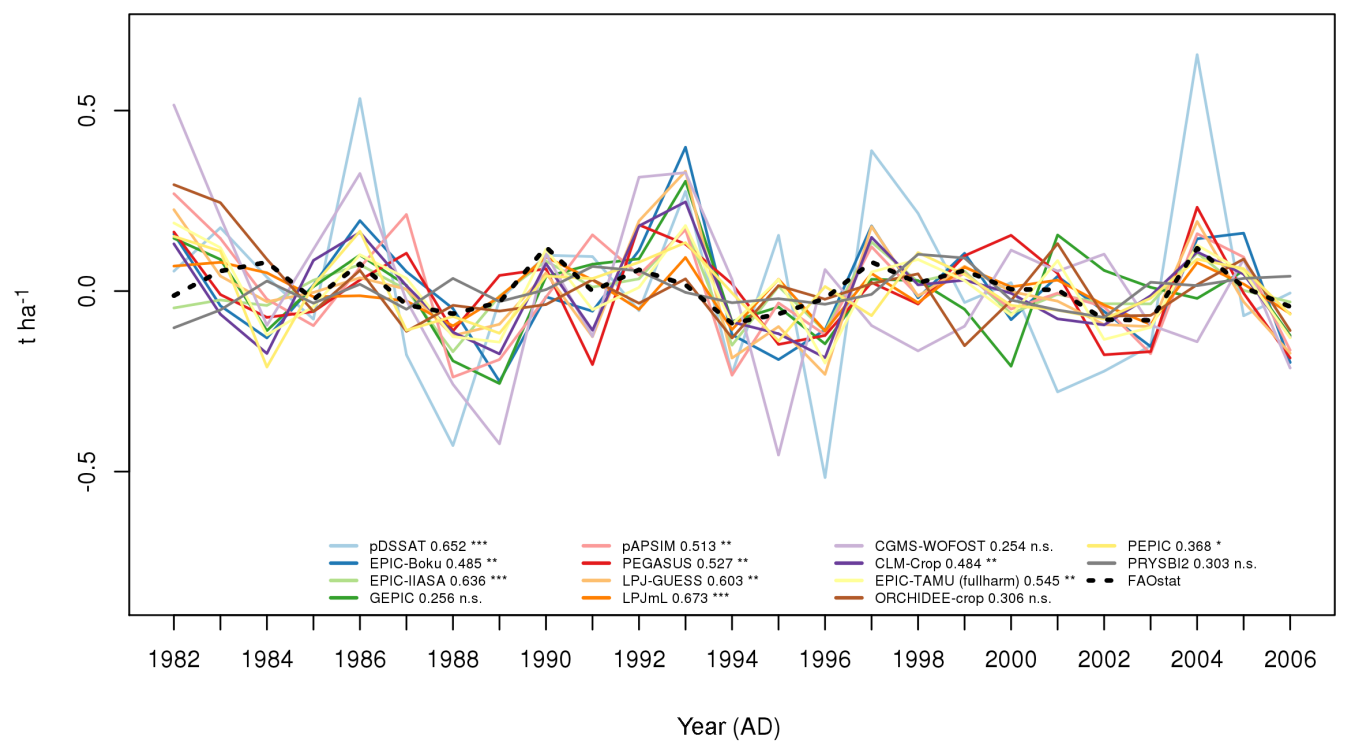

Figure 2. As Fig. 1 but for wheat.

There are also great differences between GGCMs concerning their absolute deviation from observed yield levels, reflecting their different setups, process representation and calibration (Tables S2-S4 in the Supplement). We find no relationship between mean bias and the ability to reproduce variability over time (time series correlation) for maize (Fig. 5), wheat (Fig. S9) and rice (Fig. S10) but a positive relation (i.e., correlation coefficients tend to be higher for larger mean bias) was found for soybean (Fig. S11).

\subsection{National scale}

National aggregated yield data are presented as time series correlation coefficients (color-coded in heatmaps) as well as the mean bias. Here we only show the top-10 producing countries for maize and display data for the other crops and for all producing countries in the supplement.

Interannual variability of most top-10 maize producing countries can be reproduced to large extent by various 


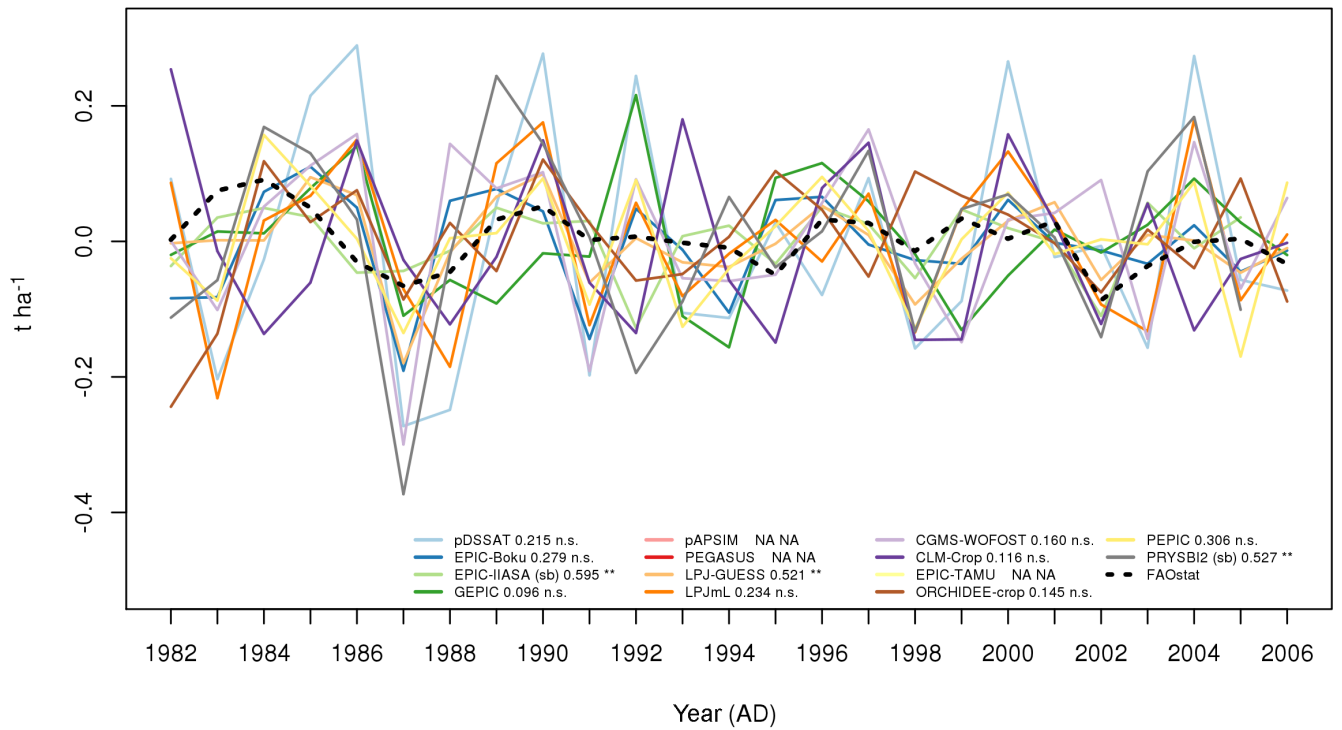

Figure 3. As Fig. 1 but for rice. EPIC-TAMU, PEGASUS and pAPSIM did not supply data for rice.

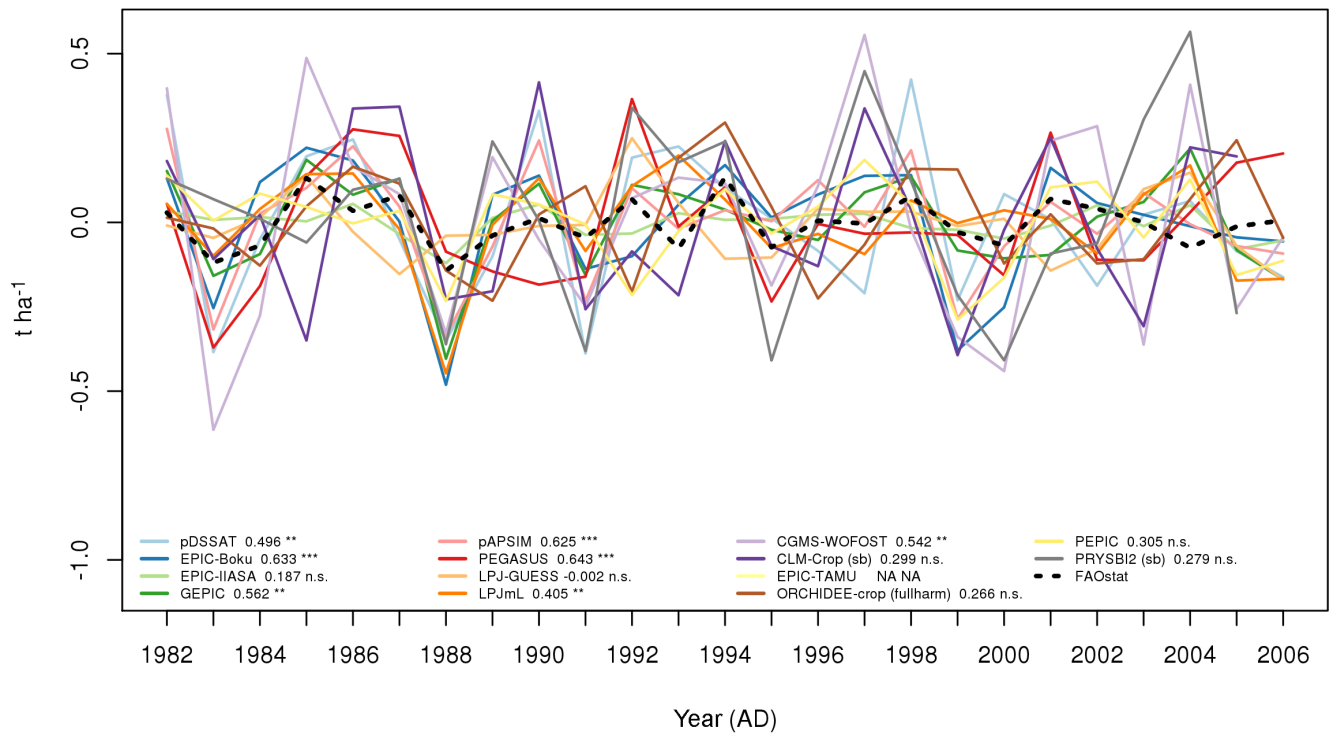

Figure 4. As Fig. 1 but for soybean. EPIC-TAMU did not supply data for soybean.

GGCMs. The interannual variability of Indonesia cannot be reproduced well by any of the models (max $r$ is 0.42 and correlation is not statistically significant in most cases), whereas the interannual variability of Argentina, France, India, South Africa and the United States can be largely reproduced by almost any GGCM-harmonization combination. To achieve good statistical correlations, some time series had to be shifted by a year, especially for Argentina, Mexico and South Africa (Fig. S12). Also for the other maize producing countries, the yield variability can be well reproduced by most GGCM-harmonization settings, and there is always at least one GGCM that can reproduce a statistically significant share of the variability (Fig. S13).

For wheat (Figs. S14-S16), rice (Figs. S17-S19) and soybean (Figs. S20-S22) a similar picture emerges. The yield variability of the top-10 producing countries can be reproduced by a large number of GGCMs, with a few exceptions (France and China for wheat; Bangladesh and Myanmar for rice; China for soybean) where only a few GGCMs are able to reproduce statistically significant shares of the yield variability in the FAO yield statistics. Likewise for wheat, rice and soybean, a statistically significant share of the yield variability can be reproduced for all producing countries covered 


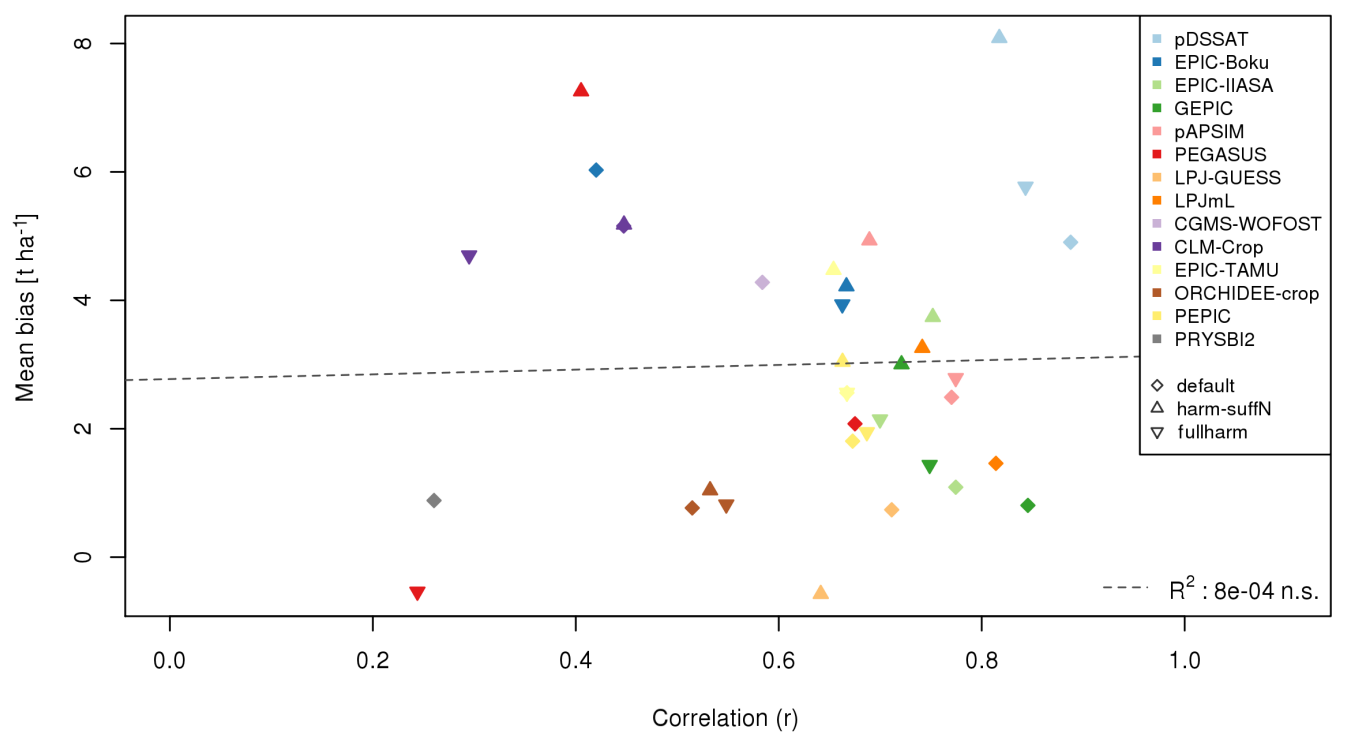

Figure 5. Relationship of global mean bias and time series correlation for maize across all GGCMs (colors) and harmonization settings (symbols). Dashed line indicates a linear fit, whose explanation power $\left(R^{2}\right)$ is given in the right-hand corner. Significance levels are as in Fig. 1.

here (best column in Figs. S16, S19, S22) and allowing for shifts in the time series can greatly improve the correlation, especially in tropical countries (e.g., Pakistan for wheat, Indonesia and Thailand for rice, soybean in India).

Other than deviating in temporal dynamics, which is tested with time series correlation analyses, GGCM simulations can also be biased compared to FAO yield statistics, typically underestimating yields in high-yielding countries and overestimating yields in low-yielding countries (Fig. 7). Some GGCMs (e.g., pDSSAT) and the harm-suffN generally tend to overestimate yields, but not in all cases (Figs. 7, S23-S26).

Aggregation to national scale does not only allow for looking into temporal dynamics of each individual country, it also allows for assessing spatial patterns in combination with temporal dynamics. By assembling national yield data series to a two-dimensional field (countries $\times$ time), we can assess the spatiotemporal correlation between simulated and FAO data as well as the variance and centered RMSD using Taylor diagrams (Taylor, 2001). Here, countries are weighted by production (FAOstat data, 2014) to avoid that small countries dominate the overall picture (see Methods). GGCMs show mixed skill when compared to FAO data, with some models having high correlation coefficients, whereas others have low or negative correlation coefficients (Fig. 8). Here, harmsuffN simulations typically show much lower correlation coefficients than the other harmonization settings. Except for one model under harm-suffN (EPIC-TAMU, Fig. 8), harmonization (fullharm, harm-suffN) eliminates any negative correlation coefficients. None of the GGCM-harmonization settings lead to negative correlation coefficients if the national differences in mean yields are ignored (Fig. S28). The Tay- lor diagram with flattened time dimension (i.e., only using one multi-annual mean per country in the analysis, Fig. S27) almost looks identical to the Taylor diagram with both the time and space dimension (Fig. 8). This disentangling of the contributions of spatial vs. temporal variability shows that the overall skill of models as presented in the Taylor diagram is dominated by the spatial signal, i.e., the differences between national mean yields outweigh the year-to-year variability around those means by far. This also explains why GGCMs with some calibration against yield levels (EPICIIASA, LPJmL, PEGASUS, PRYSBI2; see Table S4) show relatively high correlation coefficients, as the differences between national means dominate the overall correlation. When the spatial differences are ignored by removing the mean yields per country (i.e., each country has a mean of zero and the correlation thus only considers the year-to-year variability around these), the GGCMs perform more similar, typically displaying correlation coefficients between 0.4 and 0.6 (Fig. S28) and often the variance becomes larger (larger standard deviation) relative to the FAO reference data set.

A similar pattern can be observed for the other crops as well. The differences in yield levels between countries dominate the overall performance in the spatiotemporal correlation (Figs. S29 vs. S30 for wheat; S32 vs. S33 for rice; S35 vs. S36 for soybean) and GGCMs perform more similar in the analysis of time-only variance (Figs. S31, S34, S37).

\subsection{Pixel scale}

At the pixel scale, reference data uncertainty increases substantially, as the two available data sets are essentially modeland observation-based interpolations of (sub-)national yield 


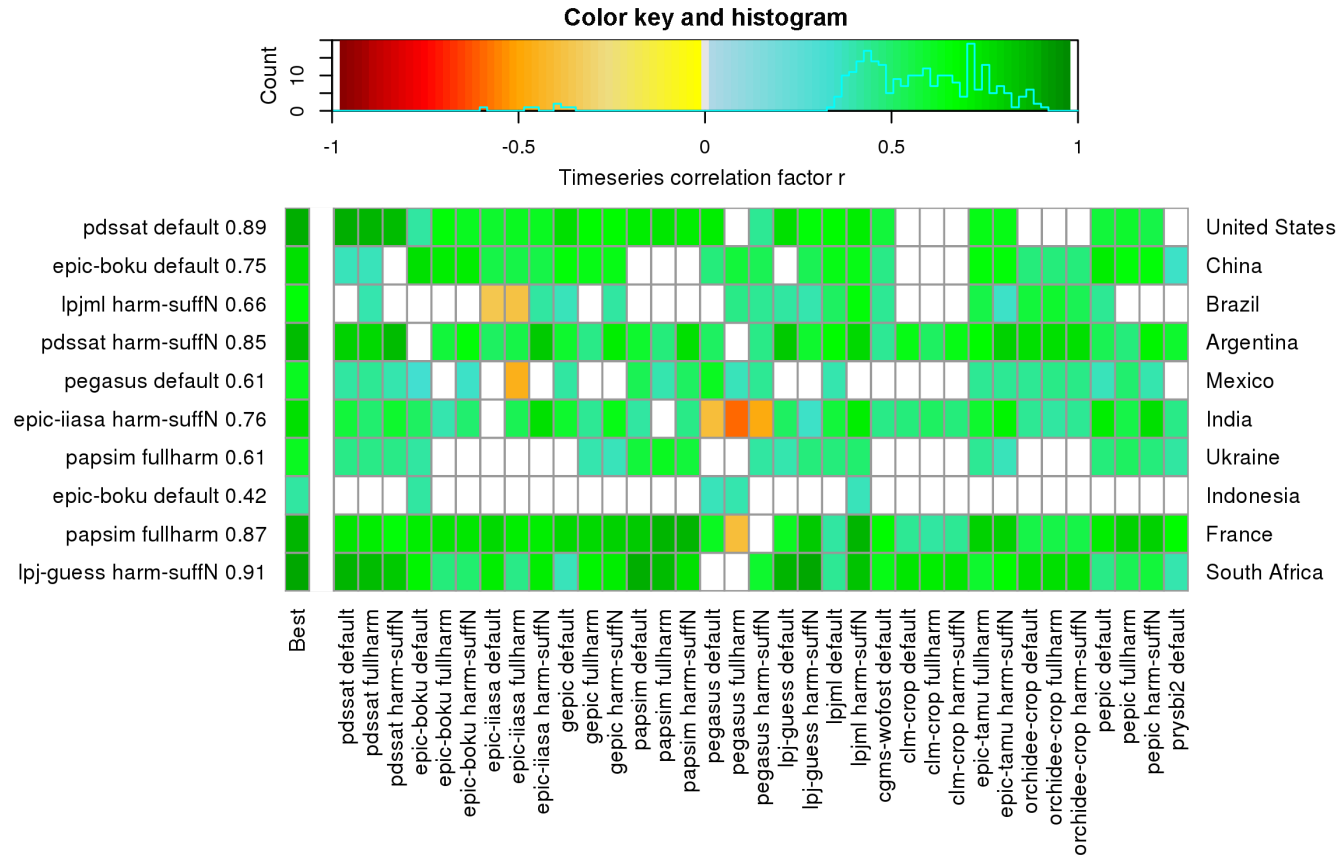

Figure 6. Time series correlation coefficients for the top-10 maize producing countries. Rows display the individual countries ordered by production; left-hand labels describe the best performing GGCMs for that country and the correlation coefficients. White boxes indicate that correlations are not statistically significant. Each column displays individual GGCM $\times$ harmonization combinations, omitting all for which data are not available. The leftmost column displays the best correlation coefficient for each country (row), corresponding to the row labels on the left. Color legend key on top includes a histogram (cyan line) that shows the distribution of correlation coefficients across the ensemble and the top-10 producing countries, excluding the "best" column.

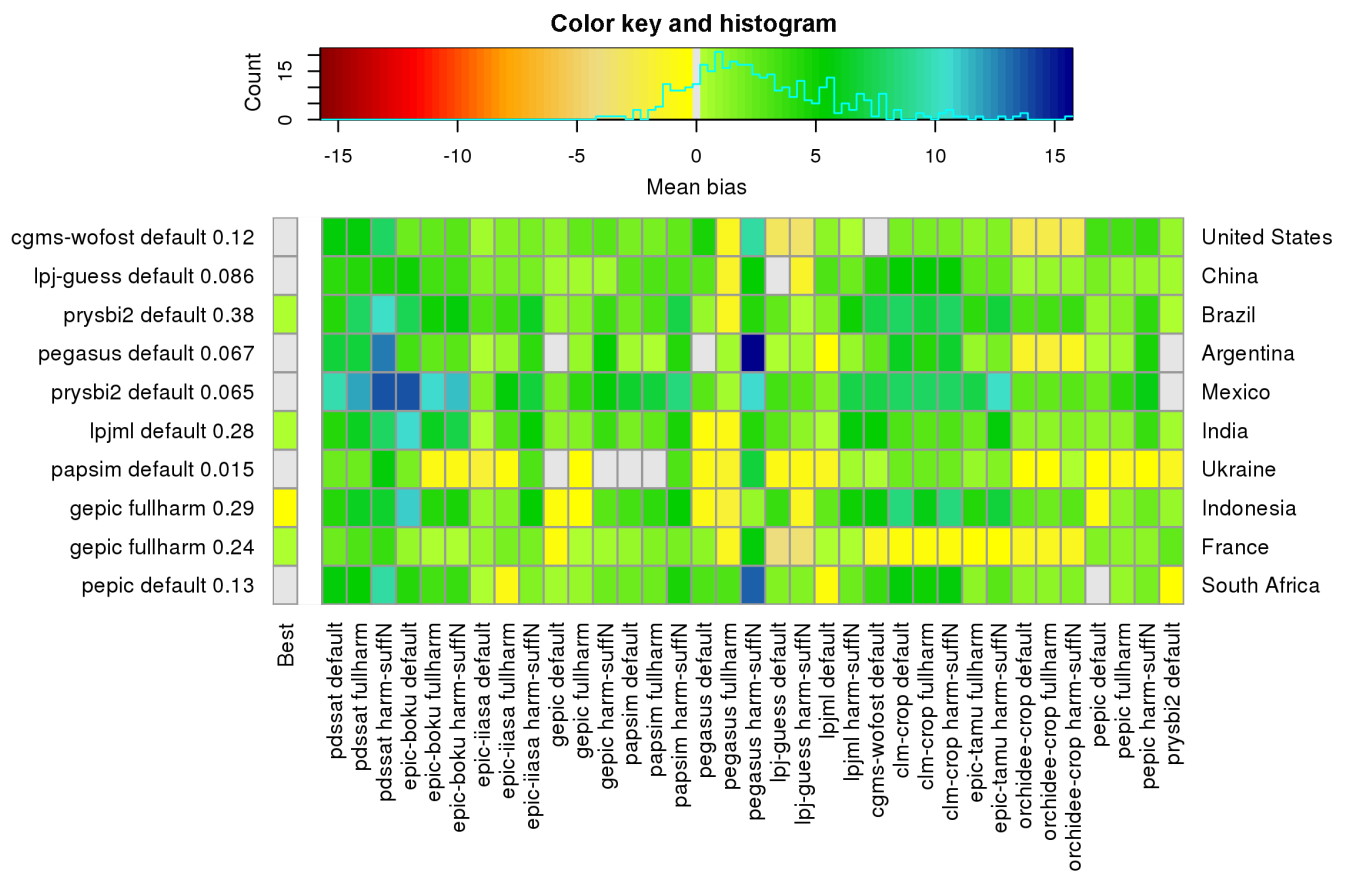

Figure 7. As Fig. 6, but for mean bias $\left(\mathrm{tha}^{-1}\right)$ of simulated yields for the top-10 producer countries for maize. 


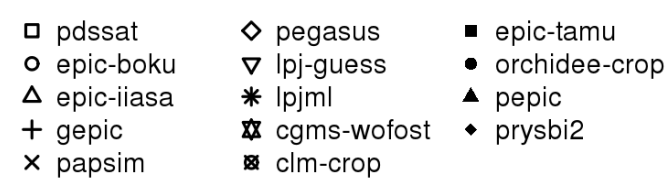

- default vs. FAOstat

- fullharm vs. FAOstat

harm-suffN vs. FAOstat

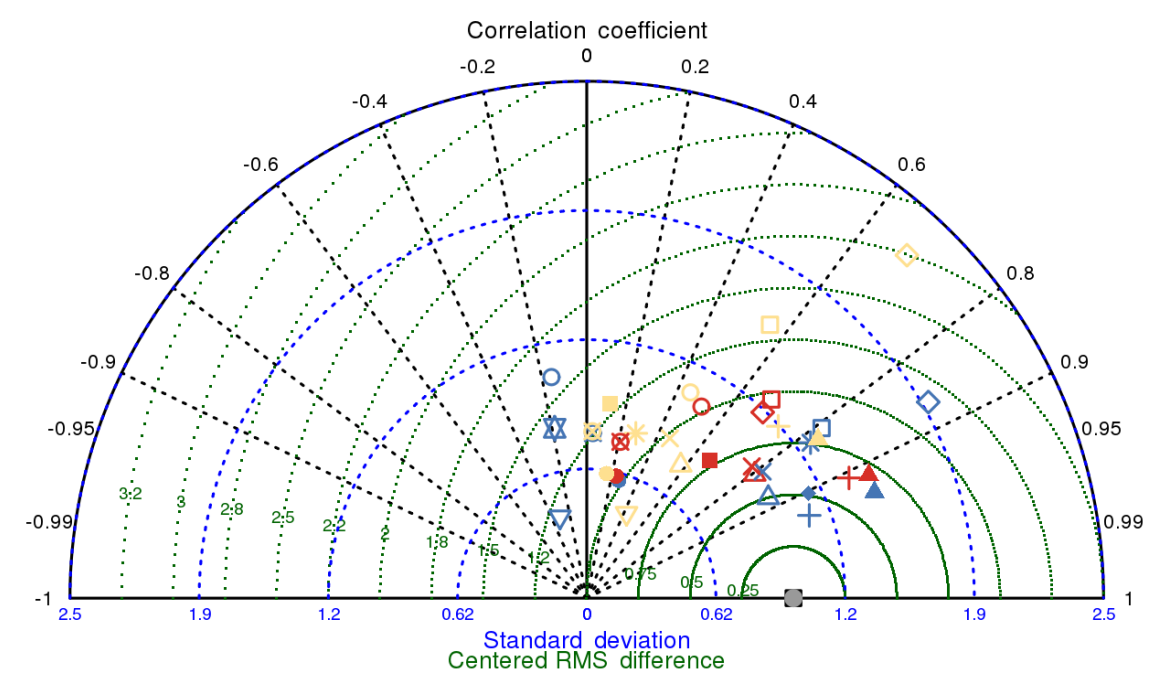

Figure 8. Taylor diagram of maize yield simulations aggregated to national level against FAO statistics data after removing trends but preserving national mean yields. A perfect match with FAO statistics data would be at the dark green box on the $x$ axis, having a normalized standard deviation of 1 (distance to origin, blue contour lines) and a correlation of 1 (angle) as well as a centered RMSD of zero (green contour lines). Symbols represent the different GGCMs, colors indicate the harmonization setting. Non-significant correlations are shaded in lighter hues. Individual countries are weighted by their maize production according to FAOstat data (2014).

statistics, and neither of the two is independent from FAO national data. Differences between the two gridded yield reference data sets (Iizumi et al., 2014b; Ray et al., 2012) are expressed via a time series correlation analysis after removing trends via a moving average (see Methods, Fig. 9).

Independent of the harmonization setting, the GGCMI model ensemble (selecting the best correlation per pixel across the different GGCMs and harmonization settings) finds statistically significant correlations $(p<0.1)$ with Ray2012 in most of the currently cropped areas for all four crops analyzed here (Fig. 10 for maize; Figs. S38-S40 for wheat, rice and soybean). The spatial patterns with high correlations are comparable to where Ray 2015 could find significant influence of weather on crop yield variability with an ensemble of 27 regression models, but the GGCMI ensemble finds statistically significant contributions of weather (the only dynamic driver in the model simulations) over a much larger area than Ray2015. The original analysis of Ray 2015 could find better correlations for large parts of China, the Corn Belt in the USA and individual countries in Africa, most notably Kenya and Zimbabwe. Contrary to the GGCMI ensemble (best per pixel), individual GGCMs find statistically significant correlations in a much smaller area, largely comparable to the 27 regression model ensemble used by Ray2015; see, e.g., pDSSAT simulations for maize in the supplement (Fig. S41). There is no eminent pattern in the performance of individual GGCMs and none of the GGCMs perform in any region significantly better than all others (see, e.g., Fig. S42 for best performing GGCM per grid cell for maize under the default setting).

Some individual GGCMs achieve similar distribution of correlation coefficients with the gridded maize yield data set of Ray2012 as the ensemble of the 27 regression models as used by Ray2015, but most perform less well (Fig. 11). As at the global-scale and national-scale aggregation level, harmonization can improve or worsen GGCM performance, depending on the GGCM.

For wheat, the GGCMI ensemble also finds statistically significant correlations for a much larger area than the regression model ensemble used by Ray2015, but correlation coefficients are often lower (e.g., in Europe) even though the spatial patterns with relatively high correlations coefficients are similar between the GGCMI ensemble and those reported by Ray2015 (see Fig. S38). As for maize, the harmonization has little effect on the ensemble skill. Also the distribution of coefficients of determination values shows that GGCMs can reach higher values for individual pixels but are generally (individually and as the total ensemble) less well correlated with the gridded Ray data set than the 27 regression models of Ray2015; see Figs. S38 and S43.

A similar picture emerges for rice, where also Ray2015 only find low correlation coefficients, whereas the GGCMI 


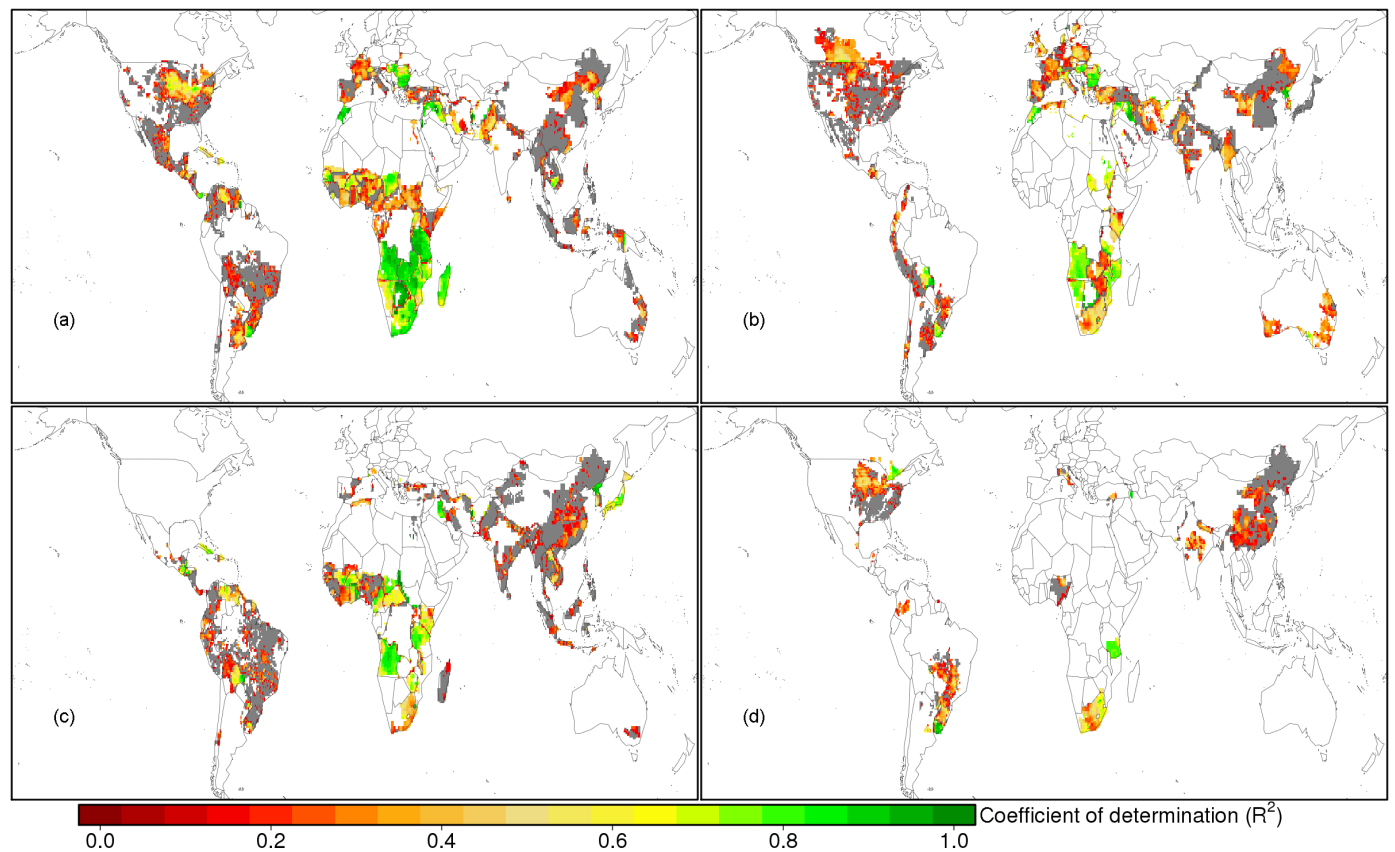

Figure 9. Analysis of time series correlation between the two gridded yield reference data sets after removing trends via a moving average (see methods). Gray areas depict areas where there is no statistically significant correlation between the two data sets $(p>0.1)$, white areas have no yield data for that crop in at least one of the two data sets. Panel (a) shows coefficients of determination $\left(R^{2}\right)$ for maize, (b) for wheat, (c) for rice, (d) for soybean.

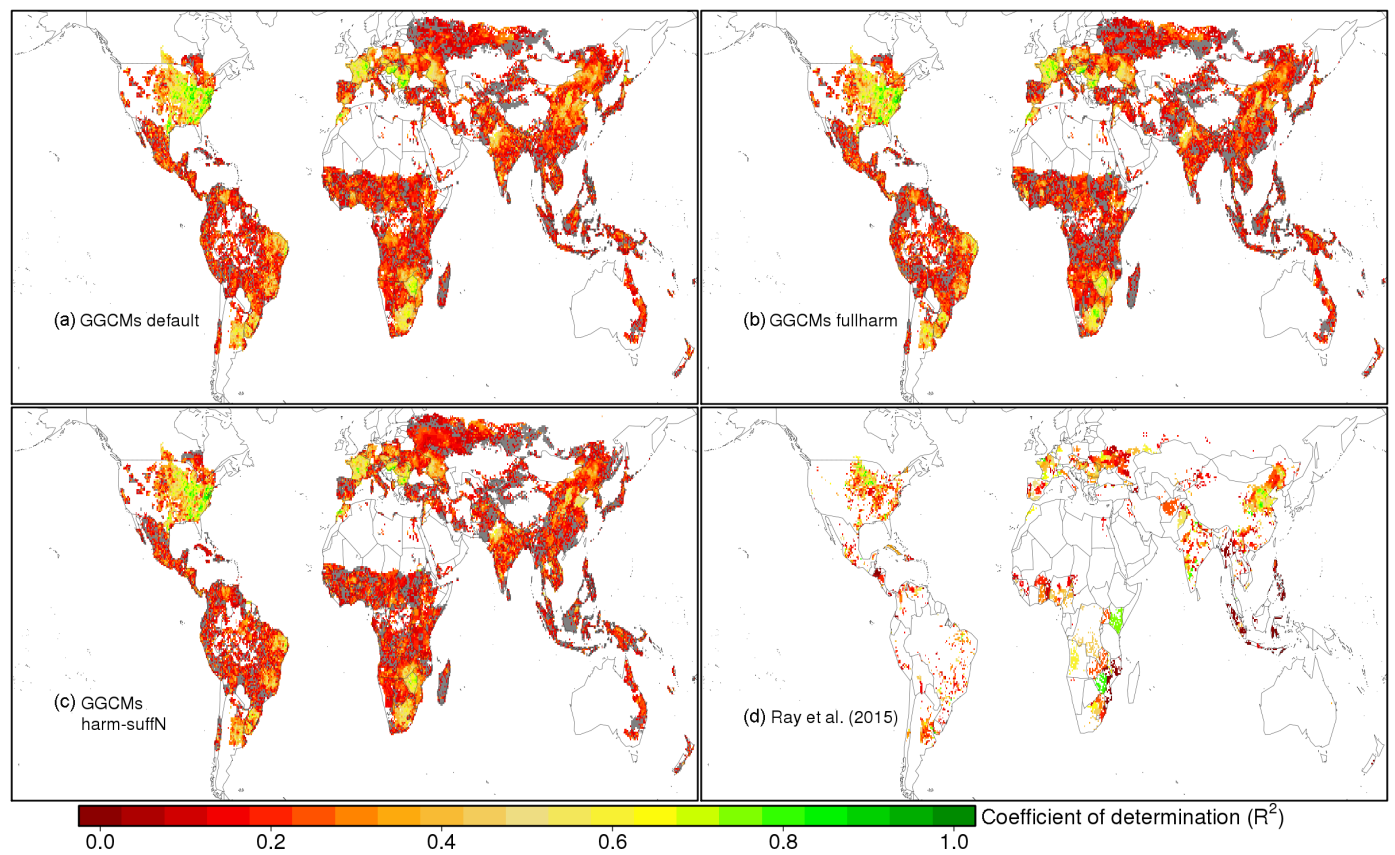

Figure 10. Analysis of time series correlation between the GGCM ensemble simulations for maize (selecting best correlation across the GGCMs per grid cell) and the Ray2012 reference data set after removing trends via a moving average (see methods). Gray areas depict areas where none of the GGCMs find a statistically significant correlation; white areas have no yield data for that crop in Ray2012 data sets. Panel (a) shows coefficients of determination $\left(R^{2}\right)$ for the default setting, (b) for the fullharm setting, (c) for the harm-suffN setting, and (d) shows the original coefficients of determination as reported by Ray et al. (2015) for an ensemble of 27 regression models. 
ensemble covers a much broader area and finds moderate correlation coefficients in South America, India and Australia, but not in China as Ray2015 do. As for wheat, individual GGCMs can reach higher coefficients of determination values than the regression model ensemble of Ray2015 for individual pixels, but generally the correlations found are weaker than for the regression model ensemble as used by Ray2015; see Figs. S39 and S44.

For soybean, the GGCMI ensemble also covers a broader range than the regression model ensemble used by Ray 2015. As for maize, the GGCMI ensemble finds equally high correlation coefficients as the regression model ensemble, with the notable exception of western Russia (Fig. S40). Soybean yield variability in the USA can be better reproduced by the GGCMI ensemble than by the regression models employed by Ray2015. Again, some individual GGCMs perform equally well as the regression model ensemble employed by Ray2015, whereas the GGCMI ensemble achieves better coefficients of determination than the regression model ensemble used by Ray2015 (Fig. S45). Also here, some GGCMs profit from harmonization, whereas others have better performance under their default setting or are not sensitive to the harmonization at all.

\section{Discussion}

\subsection{Benchmark: what to expect from GGCMs}

It is implausible to expect crop models to reproduce vast shares of yield variability and spatial patterns of crop yields given their coarse resolution, reliance on static inputs and reliance on weather data when this is but one driver of true yield variability. This is particularly true for low-input regions where many other elements, such as unsuitable management or pest outbreaks, may contribute substantially to yield variability. It is questionable if the statistical analysis of Ray2015 should define the expectations for crop model performance as their regression models are driven with rather aggregate weather information (precipitation and temperature of either the growing season or of the 12 month preceding harvest). As GGCMs often find stronger influence of weather variability than Ray2015, especially for maize and soy, it is plausible to assume that weather variability is at least as important as described by Ray2015. On the other hand, regression models can be derived from many time series and as none of the GGCMs can reproduce the strong influence of weather variability on crop yields as, e.g., reported for maize in Kenya or soybean in Russia (Ray et al., 2015), these strong relationships may be statistical artifacts or based on other weather-related dynamics that are not captured by the GGCMs, such as weather-related pest outbreaks (e.g., Esbjerg and Sigsgaard, 2014). Similar considerations apply for national and global-scale performance. However, also here it can be generally expected that weather variabil- ity is more important for yield variability in countries with high-input agriculture than in low-input countries. GGCM simulations should not be expected to reproduce yield variability of countries that do not directly report production and harvested area to the FAO and where data gaps are filled with FAO estimates (Folberth et al., 2012).

Gridded crop models make a number of simplifications, such as homogeneous management across larger areas, including soils, sowing dates and varieties. Within individual farming regions, sowing varies by days to even weeks as sowing dates are subject to a number of weather-induced conditions (e.g., soil wetness, soil temperature) and the timely availability of labor, machinery and farmers may chose different varieties to grow. The mixture of management practices within regions thus buffers observed variability in the region's yield records, as the diversity should cancel out the variability to some extent when aggregated to a region average. GGCMs on the contrary implement highly homogeneous systems that tend to overestimate variability, allowing for no or little variation in sowing dates across the years or within larger regions (Sacks et al., 2010) and assuming no change in crop varieties across the simulation period of 31 years. This variety selection not only contributes to the technology-driven trend in crop yields, which we have removed here (see Methods), but may also alter the crops' response to adverse environmental conditions. The model simplifications also encompass simplified assumptions on the distribution of fertilizers and varieties, which should affect not only the temporal dynamics simulated but also the spatial patterns of crop yields.

\subsection{GGCM performance}

Maize and soybean are the crops where the GGCMs show the best skill in reproducing reference data variability, followed by wheat and rice. The separation of temporal and spatial variability shows that the spatial variability dominates the overall variability in data simply because the differences between national yields are typically greater than those between individual years within countries. GGCMs that perform some level of calibration against national data therefore score relatively high in correlation coefficients (e.g., Fig. 8) but not necessarily for greater model skill as the national differences are imposed in the calibration process. If nutrients are assumed to be non-limiting (harm-suffN), the reproduction of spatial patterns is reduced and these simulations (orange symbols in, e.g., Fig. S27) are therefore typically less extreme in comparison to the default settings (blue in, e.g., Fig. S27) and closer to the analysis of only temporal dynamics (e.g., Fig. S28). Harmonization of management assumptions affects only in some cases the time series correlation in individual countries (e.g., Fig. 6). Simulations with no nutrient limitation typically lead to a greater mean bias in yield simulations (e.g., Fig. 7) but not necessarily to large changes in time series correlation, suggesting that calibration or mean 


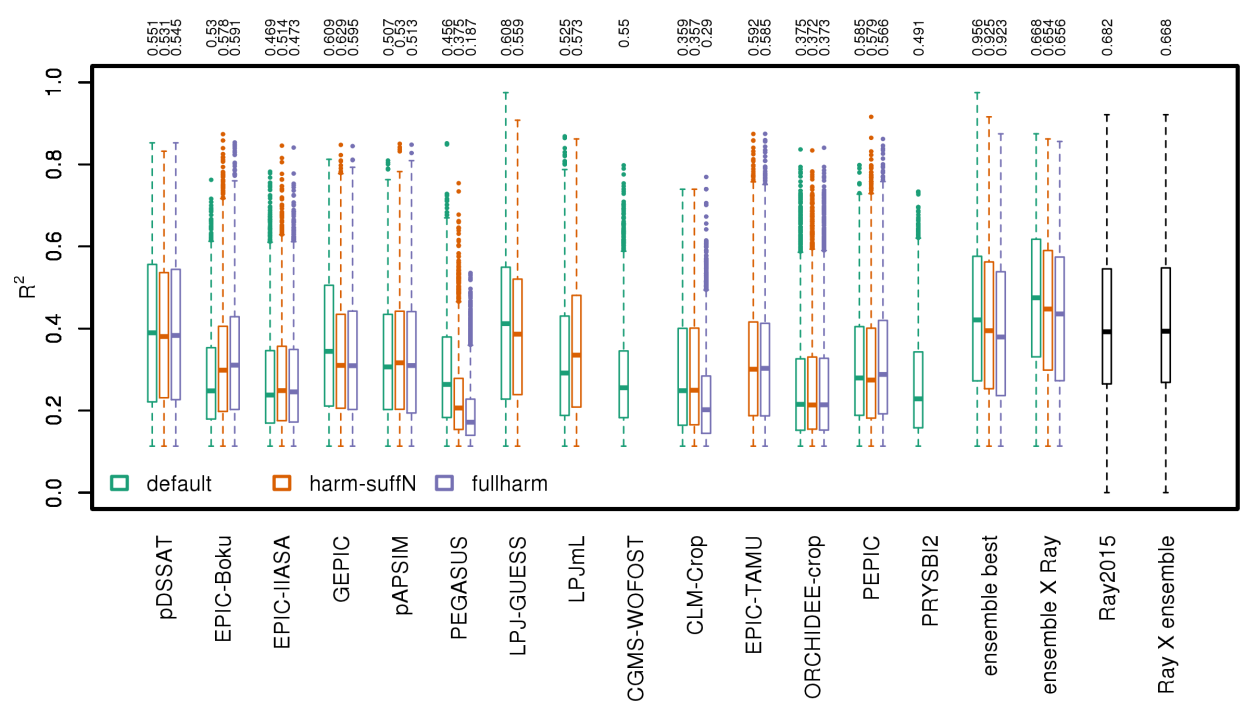

Figure 11. Box plot of $R^{2}$ distribution for each GGCM-harmonization setting for maize. Boxes span the interquartile range (25-75 percentiles); whiskers expand to the most remote value within 1.5 times the interquartile range. Values outside this range are considered outliers and are depicted as dots. The "ensemble best" shows the GGCMI skill-based (correlation coefficient) ensemble, "ensemble X Ray" is the same but only for those pixels where, and both are not independent from FAO national data also report significant correlations, "Ray2015" is the distribution of values as published by Ray et al. (2015), "Ray X ensemble" is as Ray2015 but only for the area where also the GGCMI ensemble reports significant correlation coefficients. The distribution is weighted by production, following the Ray 2012 data set. Numbers at the top describe the fraction of the total harvested area for which significant correlations could be found, which ranges between $96 \%$ (ensemble best, default), $63 \%$ and $19 \%$ for the individual GGCMs, and $68 \%$ for Ray et al. (2015).

biases often do not affect the model's skill to respond to interannual variation in weather conditions. However, it also often leads to greater variance in the time series (orange symbols move outwards relative to blue symbols in Figs. S28, S31, S34, S37). The effect of harmonization is dependent not only on the individual GGCM's sensitivity to these assumptions but also to the difference between the default and the harmonized settings with respect to growing season and fertilizer input.

For maize and soy, the GGCMI ensemble outperforms an ensemble of 27 regression models (Ray et al., 2015) with respect to area with significant correlation and to correlation coefficients (Figs. 11 and S45), indicating that model performance is good. As there are still regions in which GGCMs are outperformed by the regression models (e.g., Kenya for maize, Russia for soybean), and because the individual GGCMs show varying skill for different regions, each of the models has sufficient room for improvement if we consider the best performing model is the benchmark for all others.

For wheat, GGCMs show less influence of weather variability than Ray2015 and should thus strive to achieve similar performance levels as the regression models used by Ray2015. The simulation of wheat is complicated by the mixture of spring and winter wheat varieties that are also grown within the same regions and where the current distinction in the models and the GGCMI growing season data may not be accurate. For future analyses, we therefore rec- ommend to perform separate simulations for spring and winter wheat.

Rice is generally not simulated with great skill by any GGCM or the overall ensemble. However, also the regression model ensemble of Ray2015 does not detect substantial influence of interannual weather variability in much of the rice growing areas, suggesting that rice production systems are currently not well represented in GGCMs and also cannot be captured well by regression models. Possible causes could be the complexity of the multiple cropping seasons in rice production (Iizumi and Ramankutty, 2015) and the assumptions on irrigation, which is especially in rice production largely irrigated.

There is considerable uncertainty in historic weather patterns, as reflected by the nine different weather data products used in GGCMI. Here we only use one of these weather data sets for which all GGCMs submitted data with different management scenarios (default, fullharm - harmonized growing periods and nutrient inputs, harm-suffN -harmonized growing periods with no nutrient stress).

\subsection{Data processing and assumptions}

There are a number of caveats with respect to the processing of data. We employ a moving average approach to remove trends from observation-based and simulated data. There are various other methods to remove trends from time series (e.g., linear or quadratic trends) that we have tested as 
well. No clear picture has emerged to what method is best as this is dependent on the individual time series. We argue that the most important aspect in this de-trending is that observation-based and simulated data are treated in the same way. Also, the moving average seems to be least dependent on assuming an underlying functional form as, e.g., linear or quadratic de-trending methods, and thus is more robust across the broad range of yield time series (global, national, grid cells). Data aggregation is based on global data sets on harvested areas per crop. Porwollik et al. (2017) have demonstrated that this can greatly affect results for individual crop $\times$ GGCM $\times$ country combinations. Here we chose to use the best-matching aggregation mask in each case, arguing that as long as none of the harvested area data sets can be excluded for quality concerns all are equally plausible and their disagreement should not be held against the crop models.

We find that shifting time series by a year can sometimes greatly improve the correlation between simulated and reference time series, e.g., converting a non-significant correlation into a highly significant $(p<0.01)$ correlation with high correlation coefficients $(r=0.89)$ for LPJ-GUESS harm-suffN maize simulations for South Africa or converting negative correlation coefficients $(r<-0.5)$ to positive $(r>0.5)$ for PEGASUS fullharm maize simulations in China (Figs. 6 and S12). We acknowledge that some of this is owing to the relatively vague definition of how FAO yields are attributed to calendar years and how this matches with assumed growing periods in the GGCM simulations. However, this seems to be an important improvement to be achieved by future global crop modeling studies. The GGCMI phase I protocols request that data are reported as a series of growing season harvests (Elliott et al., 2015) rather than calendar years to avoid complications with harvest year attribution if harvest occurs around the end of the calendar year. Moreover, years are removed from the record if sowing occurred during the spinup; i.e., part of the growing season is not within the supplied weather input. Data reporting of future GGCMI simulations will have to be improved to better enable a direct matching of simulated and reference time series. If time series correlation at the global scale could be improved by time shifts, obviously the correlation would be even more improved, if individual country time series would have been adjusted as needed before aggregation rather than shifting the aggregated time series. However, this is beyond the scope of the study here.

\subsection{Implications for future crop model development and analyses}

Further model development and improvement is needed in collaboration with field-scale modeling approaches (Asseng et al., 2013; Bassu et al., 2014; Li et al., 2015) and experimentalists (Boote et al., 2013). Improvements are also wanted for the representation and aggregation of soils in
GGCM simulations (Folberth et al., 2016b) and management including growing season data and fertilizer types, amounts and timing (Hutchings et al., 2012). But also information on soil management, crop varieties, crop rotations, and actual irrigation amounts and schemes is presently not or only incompletely available, and better information could greatly inform global crop modeling. Scrutinizing underlying reasons (e.g., the detail on management considered in the simulations) for good or poor model performance is, however, beyond the capabilities of this study, and the individual modeling groups are requested to investigate their model's strengths and weaknesses. The overall model evaluation and the GGCMI phase I modeling data set (Elliott et al., 2015) enabled such analyses but cannot be conducted centrally. The work by Folberth et al. (2016a) is a good example of how the underlying reasons for differences in model performance can be identified for individual crop models.

Also, yield statistics in themselves are not a good reference data set for dissecting model functionality as errors in various processes, such as gross primary production, respiration, allocation of photosynthate, soil dynamics and crop stress response, can compensate each other in the formation of yield. Site data measurements provide data on not only targeted experiments (as, e.g., the FACE experiments; see, e.g., Leakey et al., 2009) but also on related water and carbon dynamics, as, e.g., eddy flux tower measurements that can help to get good simulation results for good reasons. Therefore, it remains crucial to also test global-scale models against detailed data from experiments to build trust in the underlying mechanisms. This point-scale evaluation of models has been performed for several of the GGCMs engaged here and is not the subject of this study (e.g., Gaiser et al., 2010; Izaurralde et al., 2006; Jones et al., 2003).

We propose that future global or large-scale gridded crop models are tested against the GGCMI model ensemble and the reference data used here to establish a benchmark for model evaluation and future model development. This cannot overcome the shortage in suitable reference data, but it provides a first benchmark against which global gridded crop models can be tested. We are well aware of the shortcomings to establish a benchmark that largely consists of modeled data (Best et al., 2015; Kelley et al., 2013), either from other models or from model-assisted interpolation of highly aggregated statistics but see no other option under current data availability. Furthermore, the benchmark should not be confused with a validation of models, but establishes a reference point against which model performance can be evaluated. Here we assume that the best-performing model currently defines the model performance that can be expected, but acknowledge that the underlying reasons for good (and poor) model performance need to be better understood in order to avoid defining statistical artifacts as a benchmark for models. 


\section{Conclusions}

Agricultural productivity is increasingly modeled at the global scale, but model setup and evaluation is hampered by the lack of high-quality input and reference data. We establish a first global crop modeling benchmark using a crop model ensemble of 14 crop modeling groups and reference data at grid cell, national and global scale. Even though crop models often demonstrate good performance in reproducing temporal and spatial patterns of observed crop yields, there is also the need to improve all models. We argue that the value of the crop model ensemble in an intercomparison study is the ability to learn from each other as models often show complimentary skill. We encourage all future crop model development to be tested against the GGCMI global crop model benchmark and thus make our evaluation framework publicly accessible at https://mygeohub.org/ groups/geoshare. This modeling intercomparison exercise provides a benchmark for facilitating model improvements by the individual modeling groups. There is substantial crop modeling skill for the simulation of maize, wheat and soybean yields at the global scale, but rice simulations are currently not preforming well and will require additional effort to improve these simulations. Ongoing collaboration with field-scale modelers and experimentalists is needed to improve model mechanisms and parameters. Finally, our results emphasize the need for continuous development and improvement of detailed agricultural data for model input and model evaluation that cover the entire global agricultural land.

Code and data availability. The code of the processing scripts is available via github at https://github.com/RDCEP/ggcmi. The evaluation pipeline is available at https://mygeohub.org/tools/ ggcmevaluation and can be used by crop modelers to evaluate their model performance in the same way as in this paper. Model output data is available via the GGCMI data archive at http://www.rdcep. org/research-projects/ggcmi.

\section{The Supplement related to this article is available online at doi:10.5194/gmd-10-1403-2017-supplement.}

Author contributions. C. Müller and J. Elliott designed the experiment and the evaluation framework in discussion with all coauthors. C. Müller, J. Elliott and J. Chryssanthacopoulos developed the code for the evaluation and data processing. C. Müller, J. Elliott, J. Balkovic, D. Deryng, C. Folberth, S. Hoek, R. C. Izaurralde, C. Jones, N. Khabarov, P. Lawrence, W. Liu, S. Olin, T. A. M. Pugh, A. Reddy, G. Sakura, E. Schmid, R. Skalsky, X. Wang and A. de Wit performed model simulations. T. Iizumi and D. K. Ray provided reference data. C. X. Song developed the online tool for model evaluation. C. Müller wrote the manuscript with contributions from all co-authors.
Competing interests. The authors declare that they have no conflict of interest.

Acknowledgements. We acknowledge the support and data provision by the Agricultural Intercomparison and Improvement Project (AgMIP). This work was completed in part with resources provided by the University of Chicago Research Computing Center. C. Müller acknowledges financial support from the MACMIT project (01LN1317A) funded through the German Federal Ministry of Education and Research (BMBF). A. Arneth and T. A. M. Pugh were supported by the European Commission's 7th Framework Programme under grant agreement no. 603542 (LUC4C) and by the Helmholtz Association through its research program ATMO. P. Ciais acknowledges support from the European Research Council Synergy grant ERC-2013-SyG-610028 IMBALANCE-P.

Edited by: M.-H. Lo

Reviewed by: two anonymous referees

\section{References}

Alfons, A. and Kraft, S.: simPopulation: Simulation of synthetic populations for surveys based on sample data, available at: https: //cran.r-project.org/src/contrib/Archive/simPopulation (last access: 1 January 2015), 2013.

Asseng, S., Ewert, F., Rosenzweig, C., Jones, J. W., Hatfield, J. L., Ruane, A. C., Boote, K. J., Thorburn, P. J., Rotter, R. P., Cammarano, D., Brisson, N., Basso, B., Martre, P., Aggarwal, P. K., Angulo, C., Bertuzzi, P., Biernath, C., Challinor, A. J., Doltra, J., Gayler, S., Goldberg, R., Grant, R., Heng, L., Hooker, J., Hunt, L. A., Ingwersen, J., Izaurralde, R. C., Kersebaum, K. C., Müller, C., Naresh Kumar, S., Nendel, C., O’Leary, G., Olesen, J. E., Osborne, T. M., Palosuo, T., Priesack, E., Ripoche, D., Semenov, M. A., Shcherbak, I., Steduto, P., Stockle, C., Stratonovitch, P., Streck, T., Supit, I., Tao, F., Travasso, M., Waha, K., Wallach, D., White, J. W., Williams, J. R., and Wolf, J.: Uncertainty in simulating wheat yields under climate change, Nature Climate Change, 3, 827-832, 2013.

Basso, B., Gargiulo, O., Paustian, K., Robertson, G. P., Porter, C., Grace, P. R., and Jones, J. W.: Procedures for Initializing Soil Organic Carbon Pools in the DSSAT-CENTURY Model for Agricultural Systems, Soil Sci. Soc. Am. J., 75, 69-78, 2011.

Bassu, S., Brisson, N., Durand, J.-L., Boote, K., Lizaso, J., Jones, J. W., Rosenzweig, C., Ruane, A. C., Adam, M., Baron, C., Basso, B., Biernath, C., Boogaard, H., Conijn, S., Corbeels, M., Deryng, D., De Sanctis, G., Gayler, S., Grassini, P., Hatfield, J., Hoek, S., Izaurralde, C., Jongschaap, R., Kemanian, A. R., Kersebaum, K. C., Kumar, N. S., Makowski, D., Müller, C., Nendel, C., Priesack, E., Pravia, M. V., Soo, H. K., Sau, F., Shcherbak, I., Tao, F., Teixeira, E., Timlin, D., and Waha, K.: Do various maize crop models give the same responses to climate change factors?, Glob. Change Biol., 20, 2301-2320, 2014.

Best, M. J., Abramowitz, G., Johnson, H. R., Pitman, A. J., Balsamo, G., Boone, A., Cuntz, M., Decharme, B., Dirmeyer, P. A., Dong, J., Ek, M., Guo, Z., Haverd, V., van den Hurk, B. J. J., Nearing, G. S., Pak, B., Peters-Lidard, C., Santanello, J. A., Stevens, L., and Vuichard, N.: The Plumbing of Land Surface 
Models: Benchmarking Model Performance, J. Hydrometeorol., 16, 1425-1442, 2015.

Bondeau, A., Smith, P. C., Zaehle, S., Schaphoff, S., Lucht, W., Cramer, W., Gerten, D., Lotze-Campen, H., Müller, C., Reichstein, M., and Smith, B.: Modelling the role of agriculture for the 20th century global terrestrial carbon balance, Glob. Change Biol., 13, 679-706, 2007.

Boote, K. J., Jones, J. W., White, J. W., Asseng, S., and Lizaso, J. I.: Putting mechanisms into crop production models, Plant Cell Environ., 36, 1658-1672, 2013.

CDO: Climate Data Operators, available at: http://www.mpimet. mpg.de/cdo, last access: 1 January 2015.

Del Grosso, S. J., Ojima, D. S., Parton, W. J., Stehfest, E., Heistemann, M., DeAngelo, B., and Rose, S.: Global scale DAYCENT model analysis of greenhouse gas emissions and mitigation strategies for cropped soils, Global Planet. Change, 67, 4450, 2009.

Deryng, D., Sacks, W. J., Barford, C. C., and Ramankutty, N.: Simulating the effects of climate and agricultural management practices on global crop yield, Global Biogeochem. Cy., 25, GB2006, doi:10.1029/2009GB003765, 2011.

Deryng, D., Conway, D., Ramankutty, N., Price, J., and Warren, R.: Global crop yield response to extreme heat stress under multiple climate change futures, Environ. Res. Lett., 9, 034011, doi:10.1088/1748-9326/9/3/034011, 2014.

de Wit, A. J. W. and van Diepen, C. A.: Crop growth modelling and crop yield forecasting using satellite-derived meteorological inputs, Int. J. Appl. Earth Obs., 10, 414-425, 2008.

Drewniak, B., Song, J., Prell, J., Kotamarthi, V. R., and Jacob, R.: Modeling agriculture in the Community Land Model, Geosci. Model Dev., 6, 495-515, doi:10.5194/gmd-6-495-2013, 2013.

Elliott, J., Deryng, D., Müller, C., Frieler, K., Konzmann, M., Gerten, D., Glotter, M., Flörke, M., Wada, Y., Best, N., Eisner, S., Fekete, B. M., Folberth, C., Foster, I., Gosling, S. N., Haddeland, I., Khabarov, N., Ludwig, F., Masaki, Y., Olin, S., Rosenzweig, C., Ruane, A. C., Satoh, Y., Schmid, E., Stacke, T., Tang, Q., and Wisser, D.: Constraints and potentials of future irrigation water availability on agricultural production under climate change, $\mathrm{P}$. Natl. Acad. Sci., 111, 3239-3244, 2014a.

Elliott, J., Kelly, D., Chryssanthacopoulos, J., Glotter, M., Jhunjhnuwala, K., Best, N., Wilde, M., and Foster, I.: The parallel system for integrating impact models and sectors (pSIMS), Environ. Model. Softw., 62, 509-516, 2014b.

Elliott, J., Müller, C., Deryng, D., Chryssanthacopoulos, J., Boote, K. J., Büchner, M., Foster, I., Glotter, M., Heinke, J., Iizumi, T., Izaurralde, R. C., Mueller, N. D., Ray, D. K., Rosenzweig, C., Ruane, A. C., and Sheffield, J.: The Global Gridded Crop Model Intercomparison: data and modeling protocols for Phase 1 (v1.0), Geosci. Model Dev., 8, 261-277, doi:10.5194/gmd-8-261-2015, 2015.

El-Sharkawy, M. A.: Overview: Early history of crop growth and photosynthesis modeling, Biosystems, 103, 205-211, 2011.

Esbjerg, P. and Sigsgaard, L.: Phenology and pest status of Agrotis segetum in a changing climate, Crop. Prot., 62, 64-71, 2014.

Ewert, F., van Ittersum, M. K., Heckelei, T., Therond, O., Bezlepkina, I., and Andersen, E.: Scale changes and model linking methods for integrated assessment of agri-environmental systems, Agr. Ecosyst. Environ., 142, 6-17, 2011.
Fader, M., Rost, S., Müller, C., Bondeau, A., and Gerten, D.: Virtual water content of temperate cereals and maize: Present and potential future patterns, J. Hydrol., 384, 218-231, 2010.

FAO: FAO Statistical Yearbook 2013, FAO, Rome, 2013.

FAOstat data: available at: http://faostat3.fao.org/home/E, last access: May 2014

Folberth, C., Gaiser, T., Abbaspour, K. C., Schulin, R., and Yang, H.: Regionalization of a large-scale crop growth model for subSaharan Africa: Model setup, evaluation, and estimation of maize yields, Agr. Ecosyst. Environ., 151, 21-33, 2012.

Folberth, C., Elliott, J., Müller, C., Balkovic, J., Chryssanthacopoulos, J., Izaurralde, R. C., Jones, C. D., Khabarov, N., Liu, W., Reddy, A., Schmid, E., Skalský, R., Yang, H., Arneth, A., Ciais, P., Deryng, D., Lawrence, P. J., Olin, S., Pugh, T. A. M., Ruane, A. C., and Wang, X.: Uncertainties in global crop model frameworks: effects of cultivar distribution, crop management and soil handling on crop yield estimates, Biogeosciences Discuss., doi:10.5194/bg-2016-527, in review, 2016 a.

Folberth, C., Skalsky, R., Moltchanova, E., Balkovic, J., Azevedo, L. B., Obersteiner, M., and van der Velde, M.: Uncertainty in soil data can outweigh climate impact signals in global crop yield simulations, Nat. Commun., 7, doi:10.1038/ncomms11872, $2016 b$.

Gaiser, T., de Barros, I., Sereke, F., and Lange, F.-M.: Validation and reliability of the EPIC model to simulate maize production in small-holder farming systems in tropical sub-humid West Africa and semi-arid Brazil, Agr. Ecosyst. Environ., 135, 318327, 2010.

Hansen, J. W. and Jones, J. W.: Scaling-up crop models for climate variability applications, Agr. Syst., 65, 43-72, 2000.

Hutchings, N. J., Reinds, G. J., Leip, A., Wattenbach, M., Bienkowski, J. F., Dalgaard, T., Dragosits, U., Drouet, J. L., Durand, P., Maury, O., and de Vries, W.: A model for simulating the timelines of field operations at a European scale for use in complex dynamic models, Biogeosciences, 9, 4487-4496, doi:10.5194/bg-9-4487-2012, 2012.

Iizumi, T. and Ramankutty, N.: How do weather and climate influence cropping area and intensity?, Global Food Security, 4, 46-50, 2015.

Iizumi, T., Sakuma, H., Yokozawa, M., Luo, J.-J., Challinor, A. J., Brown, M. E., Sakurai, G., and Yamagata, T.: Prediction of seasonal climate-induced variations in global food production, Nature Climate Change, 3, 904-908, 2013.

Iizumi, T., Luo, J.-J., Challinor, A. J., Sakurai, G., Yokozawa, M., Sakuma, H., Brown, M. E., and Yamagata, T.: Impacts of El Niño Southern Oscillation on the global yields of major crops, Nat. Commun., 5, doi:10.1038/ncomms4712, 2014a.

Iizumi, T., Yokozawa, M., Sakurai, G., Travasso, M. I., Romanenkov, V., Oettli, P., Newby, T., Ishigooka, Y., and Furuya, J.: Historical changes in global yields: major cereal and legume crops from 1982 to 2006, Global Ecol. Biogeogr., 23, 346-357, 2014b.

Izaurralde, R. C., Williams, J. R., McGill, W. B., Rosenberg, N. J., and Jakas, M. C. Q.: Simulating soil C dynamics with EPIC: Model description and testing against long-term data, Ecol. Model., 192, 362-384, 2006.

Izaurralde, R. C., McGill, W. B., and Williams, J. R.: Chapter 17 - Development and Application of the EPIC Model for Carbon Cycle, Greenhouse Gas Mitigation, and Biofuel Studies, in: 
Managing Agricultural Greenhouse Gases, edited by: Liebig, M. A., Franzluebbers, A. J., and Follett, R. F., Academic Press, San Diego, 2012.

Jones, J. W., Hoogenboom, G., Porter, C. H., Boote, K. J., Batchelor, W. D., Hunt, L. A., Wilkens, P. W., Singh, U., Gijsman, A. J., and Ritchie, J. T.: The DSSAT cropping system model, Eur. J. Agron., 18, 235-265, 2003.

Keating, B. A., Carberry, P. S., Hammer, G. L., Probert, M. E., Robertson, M. J., Holzworth, D., Huth, N. I., Hargreaves, J. N. G., Meinke, H., Hochman, Z., McLean, G., Verburg, K., Snow, V., Dimes, J. P., Silburn, M., Wang, E., Brown, S., Bristow, K. L., Asseng, S., Chapman, S., McCown, R. L., Freebairn, D. M., and Smith, C. J.: An overview of APSIM, a model designed for farming systems simulation, Eur. J. Agron., 18, 267-288, 2003.

Kelley, D. I., Prentice, I. C., Harrison, S. P., Wang, H., Simard, M., Fisher, J. B., and Willis, K. O.: A comprehensive benchmarking system for evaluating global vegetation models, Biogeosciences, 10, 3313-3340, doi:10.5194/bg-10-3313-2013, 2013.

Kucharik, C. J. and Ramankutty, N.: Trends and Variability in U.S. Corn Yields Over the Twentieth Century, Earth Interact., 9, 1-29, 2005.

Leakey, A. D. B., Ainsworth, E. A., Bernacchi, C. J., Rogers, A., Long, S. P., and Ort, D. R.: Elevated $\mathrm{CO}_{2}$ effects on plant carbon, nitrogen, and water relations: six important lessons from FACE, J. Exp. Bot., 60, 2859-2876, 2009.

Lemon, J.: Plotrix: a package in the red light district of R, R-News, 6, 8-12, 2006.

Lesk, C., Rowhani, P., and Ramankutty, N.: Influence of extreme weather disasters on global crop production, Nature, 529, 84-87, 2016.

Li, T., Hasegawa, T., Yin, X., Zhu, Y., Boote, K., Adam, M., Bregaglio, S., Buis, S., Confalonieri, R., Fumoto, T., Gaydon, D., Marcaida, M., Nakagawa, H., Oriol, P., Ruane, A. C., Ruget, F., Singh, B., Singh, U., Tang, L., Tao, F., Wilkens, P., Yoshida, H., Zhang, Z., and Bouman, B.: Uncertainties in predicting rice yield by current crop models under a wide range of climatic conditions, Glob. Change Biol., 21, 1328-1341, 2015.

Lindeskog, M., Arneth, A., Bondeau, A., Waha, K., Seaquist, J., Olin, S., and Smith, B.: Implications of accounting for land use in simulations of ecosystem carbon cycling in Africa, Earth Syst. Dynam., 4, 385-407, doi:10.5194/esd-4-385-2013, 2013.

Liu, J., Williams, J. R., Zehnder, A. J. B., and Yang, H.: GEPIC - modelling wheat yield and crop water productivity with high resolution on a global scale, Agr. Syst., 94, 478-493, 2007.

Liu, W., Yang, H., Folberth, C., Wang, X., Luo, Q., and Schulin, R.: Global investigation of impacts of PET methods on simulating crop-water relations for maize, Agr.Forest Meteorol., 221, 164$175,2016$.

Müller, C. and Robertson, R.: Projecting future crop productivity for global economic modeling, Agr. Econ., 45, 37-50, 2014.

Mueller, N. D., Gerber, J. S., Johnston, M., Ray, D. K., Ramankutty, N., and Foley, J. A.: Closing yield gaps through nutrient and water management, Nature, 490, 254-257, 2012.

Nelson, G. C., Valin, H., Sands, R. D., Havlík, P., Ahammad, H., Deryng, D., Elliott, J., Fujimori, S., Hasegawa, T., Heyhoe, E., Kyle, P., Von Lampe, M., Lotze-Campen, H., Mason d'Croz, D., van Meijl, H., van der Mensbrugghe, D., Müller, C., Popp, A., Robertson, R., Robinson, S., Schmid, E., Schmitz, C., Tabeau, A., and Willenbockel, D.: Climate change effects on agriculture:
Economic responses to biophysical shocks, P. Natl. Acad. Sci., 111, 3274-3279, 2014a.

Nelson, G. C., van der Mensbrugghe, D., Blanc, E., Calvin, K., Hasegawa, T., Havlík, P., Kyle, P., Lotze-Campen, H., von Lampe, M., Mason d'Croz, D., van Meijl, H., Müller, C., Reilly, J., Robertson, R., Sands, R. D., Schmitz, C., Tabeau, A., Takahashi, K., and Valin, H.: Agriculture and Climate Change in Global Scenarios: Why Don't the Models Agree, Agr. Econ., 45, 85-101, 2014b.

Osborne, T., Rose, G., and Wheeler, T.: Variation in the global-scale impacts of climate change on crop productivity due to climate model uncertainty and adaptation, Agr. Forest Meteorol., 170, 183-194, 2013.

Pongratz, J., Lobell, D. B., Cao, L., and Caldeira, K.: Crop yields in a geoengineered climate, Nature Climate Change, 2, 101-105, 2012.

Portmann, F. T., Siebert, S., and Döll, P.: MIRCA2000-Global monthly irrigated and rainfed crop areas around the year 2000: A new high-resolution data set for agricultural and hydrological modeling, Global Biogeochem. Cy., 24, Gb1011, doi:10.1029/2008gb003435, 2010.

Porwollik, V., Müller, C., Elliott, J., Chryssanthacopoulos, J., Iizumi, T., Ray, D. K., Ruane, A. C., Arneth, A., Balkovič, J., Ciais, P., Deryng, D., Folberth, C., Izaurralde, R. C., Jones, C. D., Khabarov, N., Lawrence, P. J., Liu, W., Pugh, T. A. M., Reddy, A., Sakurai, G., Schmid, E., Wang, X., de Wit, A., and Wu, X. Spatial and temporal uncertainty of crop yield aggregations, Eur. J. Agron., doi:10.1016/j.eja.2016.08.006, in press, 2017.

Ray, D. K., Ramankutty, N., Mueller, N. D., West, P. C., and Foley, J. A.: Recent patterns of crop yield growth and stagnation, Nat. Commun., 3, 7, doi:10.1038/ncomms2296, 2012.

Ray, D. K., Gerber, J. S., MacDonald, G. K., and West, P. C.: Climate variation explains a third of global crop yield variability, Nat. Commun., 6, doi:10.1038/ncomms6989, 2015.

Rosenzweig, C. and Parry, M. L.: Potential impact of climate change on world food supply, Nature, 367, 133-138, 1994.

Rosenzweig, C., Jones, J. W., Hatfield, J. L., Ruane, A. C., Boote, K. J., Thorburne, P., Antle, J. M., Nelson, G. C., Porter, C., Janssen, S., Asseng, S., Basso, B., Ewert, F., Wallach, D., Baigorria, G., and Winter, J. M.: The Agricultural Model Intercomparison and Improvement Project (AgMIP): Protocols and pilot studies, Agr. Forest Meteorol., 170, 166-182, 2013.

Rosenzweig, C., Elliott, J., Deryng, D., Ruane, A. C., Müller, C., Arneth, A., Boote, K. J., Folberth, C., Glotter, M., Khabarov, N., Neumann, K., Piontek, F., Pugh, T. A. M., Schmid, E., Stehfest, E., Yang, H., and Jones, J. W.: Assessing agricultural risks of climate change in the 21 st century in a global gridded crop model intercomparison, P. Natl. Acad. Sci. USA, 111, 32683273, 2014.

Rötter, R. P., Carter, T. R., Olesen, J. E., and Porter, J. R.: Cropclimate models need an overhaul, Nature Climate Change, 1, 175-177, 2011.

Ruane, A. C., Goldberg, R., and Chryssanthacopoulos, J.: Climate forcing datasets for agricultural modeling: Merged products for gap-filling and historical climate series estimation, Agr. Forest Meteorol., 200, 233-248, 2015.

Russell, E. J.: A History of Agricultural Science in Great Britain, 1620-1954, Allen \& Unwin, 1966. 
Sacks, W. J., Deryng, D., Foley, J. A., and Ramankutty, N.: Crop planting dates: an analysis of global patterns, Global Ecol. Biogeogr., 19, 607-620, 2010.

Sakurai, G., Iizumi, T., Nishimori, M., and Yokozawa, M.: How much has the increase in atmospheric $\mathrm{CO}_{2}$ directly affected past soybean production?, Scientific Reports, 4, 4978, doi:10.1038/srep04978, 2014.

Sheffield, J., Goteti, G., and Wood, E. F.: Development of a 50-Year High-Resolution Global Dataset of Meteorological Forcings for Land Surface Modeling, J. Climate, 19, 3088-3111, 2006.

Siebert, S., Kummu, M., Porkka, M., Döll, P., Ramankutty, N., and Scanlon, B. R.: A global data set of the extent of irrigated land from 1900 to 2005, Hydrol. Earth Syst. Sci., 19, 1521-1545, doi:10.5194/hess-19-1521-2015, 2015.

Smith, B., Prentice, I. C., and Sykes, M. T.: Representation of vegetation dynamics in the modelling of terrestrial ecosystems: comparing two contrasting approaches within European climate space, Global Ecol. Biogeogr., 10, 621-637, 2001.

Spiertz, H.: Agricultural sciences in transition from 1800 to 2020 : Exploring knowledge and creating impact, Eur. J. Agron., 59, 96-106, 2014.

Stehfest, E., Heistermann, M., Priess, J. A., Ojima, D. S., and Alcamo, J.: Simulation of global crop production with the ecosystem model DayCent, Ecol. Model., 209, 203-219, 2007.

Taylor, K. E.: Summarizing multiple aspects of model performance in a single diagram, J. Geophys. Res.-Atmos., 106, 7183-7192, 2001.

Thenkabail, P. S., Biradar, C. M., Noojipady, P., Dheeravath, V., Li, Y., Velpuri, M., Gumma, M., Gangalakunta, O. R. P., Turral, H., Cai, X., Vithanage, J., Schull, M. A., and Dutta, R.: Global irrigated area map (GIAM), derived from remote sensing, for the end of the last millennium, Int. J. Remote Sens., 30, 3679-3733, 2009.

Thoning, K. W., Tans, P. P., and Komhyr, W. D.: Atmospheric carbon dioxide at Mauna Loa Observatory: 2. Analysis of the NOAA GMCC data, 1974-1985, J. Geophys. Res.-Atmos., 94, 8549-8565, 1989.

van Bussel, L. G. J., Stehfest, E., Siebert, S., Müller, C., and Ewert, F.: Simulation of the phenological development of wheat and maize at the global scale, Global Ecol. Biogeogr., 24, 10181029, 2015.
Waha, K., van Bussel, L. G. J., Müller, C., and Bondeau, A.: Climate-driven simulation of global crop sowing dates, Global Ecol. Biogeogr., 21, 247-259, 2012.

Warnes, G. R., Bolker, B., Bonebakker, L., Gentleman, R., Huber, W., Liaw, A., Lumley, T., Maechler, M., Magnusson, A., Moeller, S., Schwartz, M., and Venables, B.: gplots: Various R Programming Tools for Plotting Data. R package version 3.0.1., available at: http://CRAN.R-project.org/package=gplots (last access: 26 January 2017), 2016.

Warszawski, L., Frieler, K., Huber, V., Piontek, F., Serdeczny, O., and Schewe, J.: The Inter-Sectoral Impact Model Intercomparison Project (ISI-MIP): Project framework, P. Natl. Acad. Sci. USA, 111, 3228-3232, 2014.

Wheeler, T. and von Braun, J.: Climate change impacts on global food security, Science, 341, 508-513, 2013.

Williams, J. R.: The EPIC model, in: Computer models of watershed hydrology, Water Resources Publications, Littleton, CO, 1995.

Wirsenius, S.: Human Use of Land and Organic materials, 2000, Thesis for the degree of Doctor of Philosophy, Department of Physical Resource Theory, Chalmers University of Technology and Göteborg University, Göteborg, Sweden, 255 pp., 2000.

Wu, X., Vuichard, N., Ciais, P., Viovy, N., de Noblet-Ducoudré, N., Wang, X., Magliulo, V., Wattenbach, M., Vitale, L., Di Tommasi, P., Moors, E. J., Jans, W., Elbers, J., Ceschia, E., Tallec, T., Bernhofer, C., Grünwald, T., Moureaux, C., Manise, T., Ligne, A., Cellier, P., Loubet, B., Larmanou, E., and Ripoche, D.: ORCHIDEE-CROP (v0), a new process-based agro-land surface model: model description and evaluation over Europe, Geosci. Model Dev., 9, 857-873, doi:10.5194/gmd-9-857-2016, 2016.

You, L., Crespo, S., Guo, Z., Koo, J., Ojo, W., Sebastian, K., Tenorio, M. T., Wood, S., and Wood-Sichra, U.: Spatial Produciton Allocation Model (SPAM) 2000 Version 3 Release 2, 2010.

You, L., Wood-Sichra, U., Fritz, S., Guo, Z., See, L., and Koo, J.: Spatial Production Allocation Model (SPAM) 2005 v2.0, available at: http://mapspam.info (last access: 16 May 2015), 2014a.

You, L., Wood, S., Wood-Sichra, U., and Wu, W.: Generating global crop distribution maps: From census to grid, Agr. Syst., 127, 5360, 2014b. 